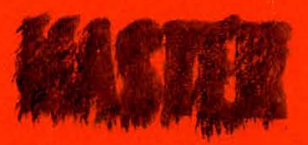

\title{
SERAPH Implementation Plans
}

Jim Castle

Wen Su

Douglas A. Dougherty

John D. Wright
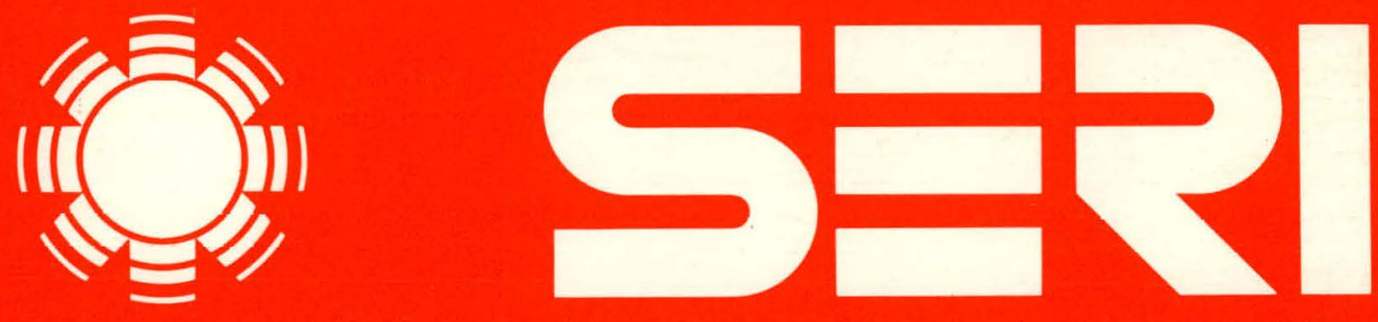

Solar Energy Research Institute

A Division of Midwest Research Institute

1536 Cole Boulevard

Golden, Colorado 80401

Operated for the

U.S. Department of Energy

under Contract No. EG-77-C-01-4042

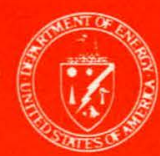




\section{DISCLAIMER}

This report was prepared as an account of work sponsored by an agency of the United States Government. Neither the United States Government nor any agency Thereof, nor any of their employees, makes any warranty, express or implied, or assumes any legal liability or responsibility for the accuracy, completeness, or usefulness of any information, apparatus, product, or process disclosed, or represents that its use would not infringe privately owned rights. Reference herein to any specific commercial product, process, or service by trade name, trademark, manufacturer, or otherwise does not necessarily constitute or imply its endorsement, recommendation, or favoring by the United States Government or any agency thereof. The views and opinions of authors expressed herein do not necessarily state or reflect those of the United States Government or any agency thereof. 


\section{DISCLAIMER}

Portions of this document may be illegible in electronic image products. Images are produced from the best available original document. 


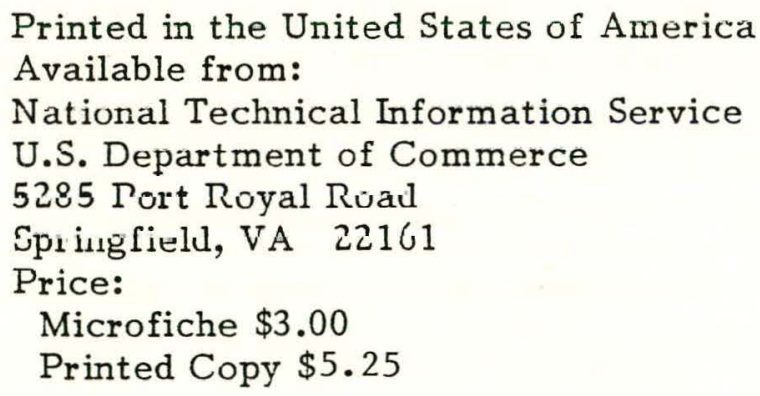

\section{NOTICE}

This report was prepared as an account of work sponsored by the United States Government. Neither the United States nor the United States Department of Energy, nor any of their employees, nor any of their contractors, subcontractors, or their employees, makes any warranty, express or implied, or assumes any legal liability or responsibility for the accuracy, completeness or usefulness of any information, apparatus, product or process disclosed, or represents that its use would not infringe privately owned rights. 
SER I /RR-34-152

UC CATEGORY: UC-59B

\section{MASTER}

SERAPH IMPLEMENTATION PLANS

JIM CASTLE

WEN SU

DOUGLAS A. DOUGHERTY

JOHN D. WRIGHT

MAY 1979

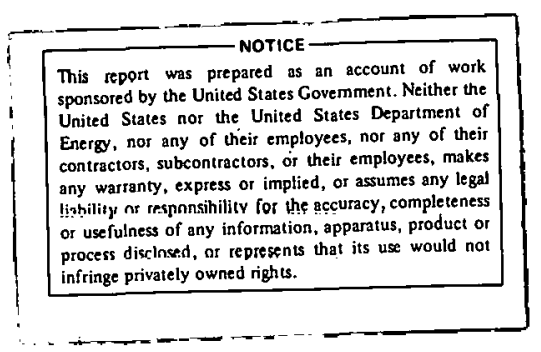

- Solar Energy Research Institute

1536 Cole Boulevard

Golden, Colorado 80401

A Division of Midwest Research Institute

Prepared for the

U.S. Department of Energy

Contract No. EG $\cdot 77 \cdot \mathrm{C} \cdot 01 \cdot 4042$ 


\section{FOREWORD}

This document describes work done on SERI Task. 3421 in planning the design, construction, and operation of the SERAPH (Solar Energy Research and Applications in Process Heat) facility at the Solar Energy Research Institute. SERAPH is a flexible tool that SERI will use to identify and resolve technical issues currently affecting the application of solar energy in the industrial environment.

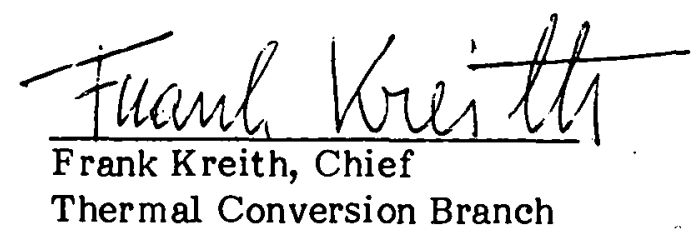

Approved for:

SOLAR ENERGY RESEARCH INSTITUTE

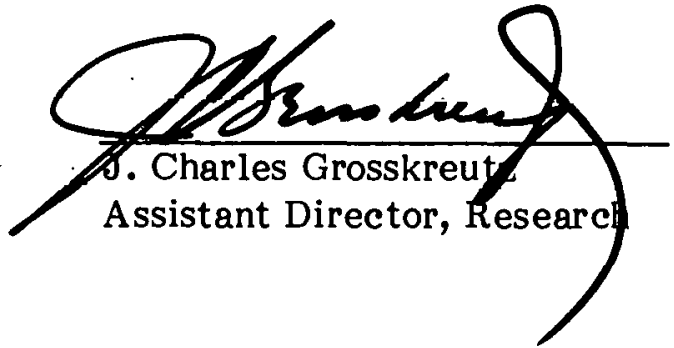




\section{TABLE OF CONTENTS}

$\underline{\text { Page }}$

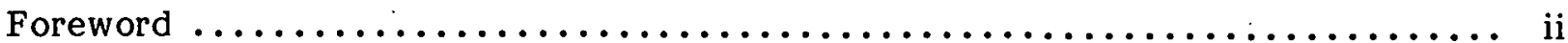

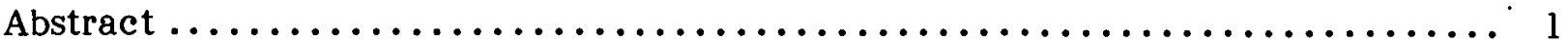

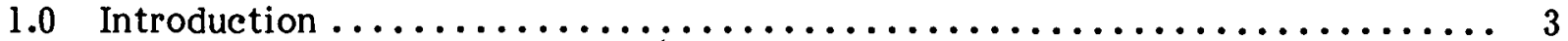

2.0 SERAPH Objectives and Design Guidelines................... 5

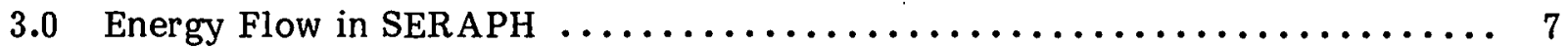

4.0 The Solar Input $\ldots \ldots \ldots \ldots \ldots \ldots \ldots \ldots \ldots \ldots \ldots \ldots \ldots \ldots \ldots \ldots \ldots \ldots$

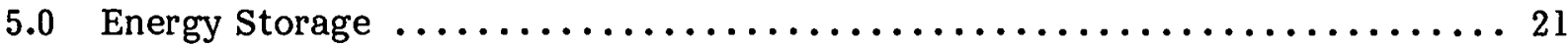

6.0 Collector Field Experimental Simulation $\ldots \ldots \ldots \ldots \ldots \ldots \ldots \ldots \ldots \ldots$

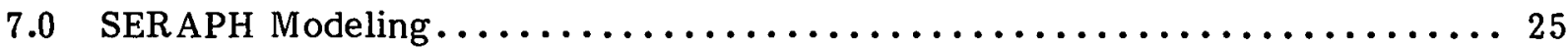

8.0 Control and Data Acquisition Subsystems $\ldots \ldots \ldots \ldots \ldots \ldots \ldots \ldots \ldots \ldots \ldots$

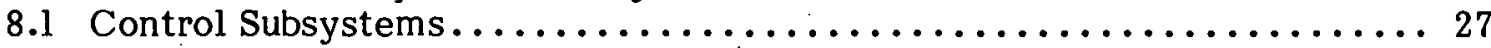

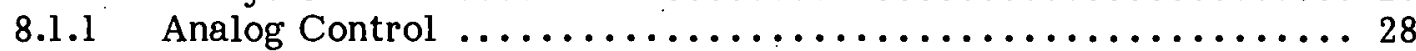

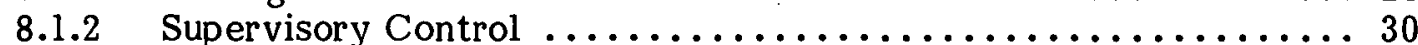

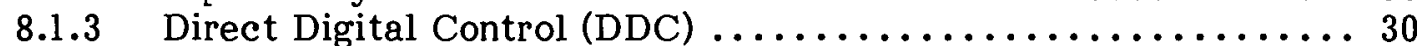

8.1.4 Sequencing and Shutdown Logic Control .............. 30

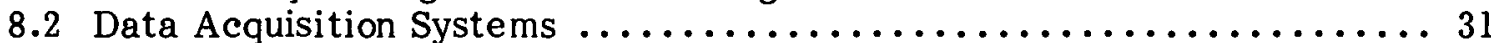

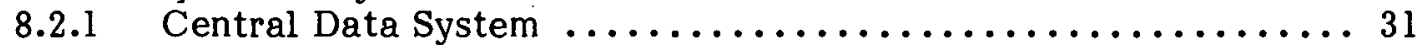

8.2.2 Field Test Site Data Subsystem ................... 31

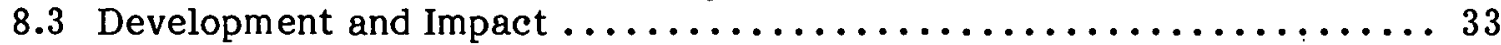

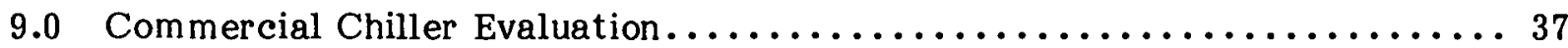

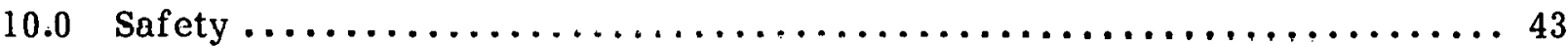

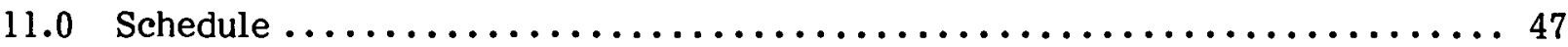

12.0 Discussion...................................... 49

13.0 References....................................... 51 


\section{LIST OF FIGURES}

Page

3-1 Energy Flow in SERAPH $\ldots \ldots \ldots \ldots \ldots \ldots \ldots \ldots \ldots \ldots \ldots \ldots \ldots \ldots \ldots . \ldots$

3-2 Conceptual Layout for the Energy Distribution System (EDS) . . . . . . . . 9

3-3 EDS Operational Modes .............................. 10

3-4 Steam Conditions Resulting from Flash Blowdown $\ldots \ldots \ldots \ldots \ldots \ldots \ldots \ldots \ldots$. 11

3-5 Solar Equipment Building ............................ 13

4-1 SERAPH Field Test Site Layout $\ldots \ldots \ldots \ldots \ldots \ldots \ldots \ldots \ldots \ldots \ldots \ldots \ldots \ldots \ldots$

4-2 SEDS Process Diagram ........................... 19

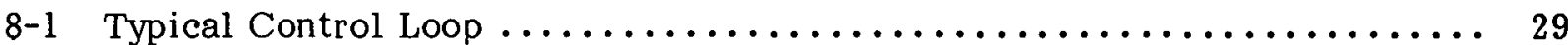

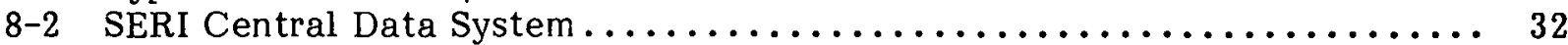

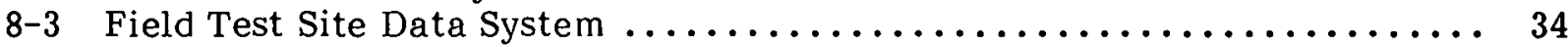

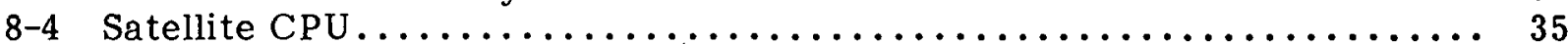

9-1 Chiller Test Installation at SERAPH $\ldots \ldots \ldots \ldots \ldots \ldots \ldots \ldots \ldots \ldots \ldots \ldots \ldots$

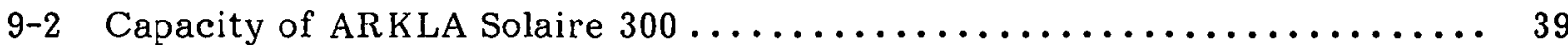

9-3 Unit Cooling Capacity of ARKLA Solaire $300 \ldots \ldots \ldots \ldots \ldots \ldots \ldots \ldots \ldots$

9-4 Loss in Capacity Due to On/Off Cycling ................... 42

10-1 Typical Light Sources and Eye Damage Thresholds ............... 44

11-1 FY79 and FY80 SERAPH Implementation Plans............... 48

\section{LIST OF TABLES}

$\underline{\text { Page }}$

3-1 Heat Transfer Fluid Selection Issues $\ldots \ldots \ldots \ldots \ldots \ldots \ldots \ldots \ldots \ldots \ldots \ldots \ldots$

4-1 Recent DOE Industrial Process Heat

Steam Awards (September/October 1978) ................... 17 


\begin{abstract}
The Solar Energy Research Institute (SERI) devotes a significant research effort to the application of solar technology in the industrial sector. It is well known that.U.S. industries consume a significant amount of energy, a large portion of which is required in a temperature range in which concentrating solar collectors work effectively. The SERAPH facility (Solar Energy Research and Applications in Process Heat) will provide at SERI the capability of addressing many of the technical issues that currently hamper industrial solar thermal energy system implementation.
\end{abstract}

The primary building blocks of SERAPH are the solar delivery subsystem, control and data acquisition subsystem (including sequencing and emergency supervision), energy distribution subsystem and two physical areas set aside for storage development and the introduction of load devices. Emphasis has been placed on creating a versatile test facility within which the solar industry can work with SERI in the development of solar systems that will be attractive to potential industrial users. SERAPH will have an initial capability of producing steam at a rate of $900 \mathrm{lb} / \mathrm{h}(410 \mathrm{~kg} / \mathrm{h})$ which corresponds to an energy delivery rate of 1.5 million Btu/h $\left(1.6 \times 10^{6} \mathrm{~kJ} / \mathrm{h}\right)$ at $430^{\circ} \mathrm{F}\left(220^{\circ} \mathrm{C}\right)$ with expansion capability to approximately $600^{\circ} \mathrm{F}\left(315^{\circ} \mathrm{C}\right)$.

The initial system controls will be analog with supervisory and direct digital control to follow. The issues to be addressed at SERAPH will be computer predictive model validation and refinement, control strategy development, solar equipment evaluation, and the accumulation of operating and maintenance experience. A consistent theme throughout the planning and operation of SERAPH is the need to develop and follow practices that are consistent with conventional industrial operating procedures. 
THIS PAGE INTENTIONALLY LEFT BLANK 
SECTION 1.0

\section{INTRODUCTION}

This report summarizes the current status of the Solar. Energy Research and Application in Process Heat (SERAPH) facility which is to be erected during FY79 and FY80 at the Solar Energy Research Institute's Field Site in Golden, Colo. SERAPH is intended to be a versatile tool with which SERI can investigate a number of unresolved issues characteristic of Industrial Process Heat (IPH) solar systems.

Large scale commercialization of solar systems in industry requires many supporting activities. The National Program Plan for Research and Development in Solar Heating and Cooling identifies for agricultural and process heat eleven paths of an evolutionary nature that are planned to extend through FY82 [1]. A previous SERI report identified the unique contribution that SERAPH could make in moving along these paths by contrasting its capabilities with other solar facilities in this country [2]. Special emphasis was placed on the testing needs in process steam (path SL in the National Program Plan) and active cooling and refrigeration (path $\mathrm{CA}$ ), both areas of significant commercialization potential.

In addition to supporting the research and development aspects of the National Program Plan, SERAPH provides a major in-house experimental capability. SERI must speak from experience when addressing real issues concerning solar energy utilization. The real-world problems identified in SERAPH will serve to focus laboratory research efforts on relevant problems.

The subsequent sections of this report describe the SERAPH plans with respect to layout and operation. Emphasis is placed on the versatile character of SERAPH. Consideration is given to a parallel thermal modeling task, development of appropriate control strategies, accommodation of a range of storage concepts, and evaluation of the operating characteristics of equipment intended for solar powered industrial applications. 
THIS PAGE INTENTIONALLY LEFT BLANK 


\section{SECTION 2.0}

\section{SERAPH OBJECTIVES AND DESIGN GUIDELINES}

SERAPH is intended to help foster the widespread use of solar thermal energy technologies in industry. The primary objectives of the facility have developed from this goal and approach it along several avenues. These objectives encompass segments of the technology which are not developed to the point at which industrial users feel confident that a solar system would exhibit the dependability and predictability they expect. Issues or processes to be addressed as primary objectives in SERAPH include:

- the selection of control strategies that address load demand profile, storage system interaction, cycling of a supplementary heat source, and the transient form of the solar input;

- the validation and refinement of analytic models commonly used for predicting solar system performance;

- the education of potential industrial users in terms of the capabilities and reguirements of industrial solar systems; and

- technology assessments such as materials behavior, reliability, operation and maintenance needs, storage system performance, and parasitic power consumption.

SERI will encourage participation by solar system and subsystem suppliers in SERAPH operations so that lessons learned can be applied directly to the advancement of the technology throughout the industry. Participation will be achieved by facility visitations, report dissemination, hardware procurement by SERI, and the publication of procurement and operational guidelines.

Secondary SERAPH objectives exist that complement the primary objectives outlined above. These items flow naturally from the capabilities presented by SERAPH once it is operational. Industry personnel may assist in day-to-day system operation over short periods as a training exercise. Solutions can be recommended for unique safety concerns presented by this type of system. New collector concepts can be evaluated as part of an entire solar system once their capability has been verified on a collector module basis. These, as well as any other secondary objectives, will be studied in proportion to the degree any one issue affects industrial solar system acceptance.

The importance of solar industrial process heat applications is such that the Department of Energy has funded a series of 18 demonstration projects throughout the United States. The projects include hot water, hot air, and lowand intermediate-temperature steam systems - all powered by a solar collector field including flat-plate and/or concentrating collectors. SERAPH will be useful because of the support it can provide to the demonstrations. Components and instrumentation scheduled for project use can be introduced into the SERAPH system for evaluation under carefully controlled and monitored conditions. Examples of such components would be a flash-blowdown steam generator and a new flowmeter configu- 
ration. The educational aspect of SERAPH can be relied upon to train operators and to assist in convincing prospective demonstration project participants to commit a portion of their energy needs to a solar system.

The primary and secondary objectives which have been identified reduce to a series of specific design guidelines which will be followed in the implementation of SERAPH. These guidelines are intended to generate an experience base in design, procurement, installation, and operation which conforms to an industry viewpoint that stresses dependability and safety. Specific design guidelines are:

- Functional separation will be maintained so that potential solar users can clearly identify those portions of SERAPH that may be applicable to their energy needs.

- Maximum flexibility will be maintained because the energy output of the facility is committed to no fixed load.
- Conventional industrial practices will be followed wherever applicable.

- Procurement efforts will be developed and/or will follow procedures that can serve as a model for subsequent industrial procurement efforts.

- Installation costs will be minimized by procuring equipment in packaged form, with special care exercised to ensure that equipment servicing is not hampered.

- Multiple energy flow paths will be incorporated so many system interactions can be investigated.

- A parallel analytical model effort will be pursued to ensure that quantitative SERAPH results can be factored into models which will be useful in predicting system performance in other industrial solar configurations. 
SECTION 3.0

\section{ENERGY FLOW IN SERAPH}

The Energy Distribution Subsystem (EDS) is that portion of the SERAPH facility responsible for moving energy between three primary functional areas: the collector field (Solar Energy Delivery Subsystem - SEDS), the storage area, and the load area. Figure 3-l indicates the way in which the placement of EDS connects the three functional areas.

For SERAPH to exhibit the versatility required to simulate numerous solar system configurations as well as operational modes within each system, it is necessary that EDS be very adaptable. It should be possible to change the mode of energy exchange among SEDS, storage, and load without requiring a significant modification to the components of EDS. A single EDS configuration that is capable of operating in a variety of modes is shown in Figure 3-2. This configuration permits, via activation of several control valves, energy transfer along these paths:

- SEDS to load,

- SEDS to storage,

- SEDS to storage and load (in parallel and in series),

- storage to load,

- storage to load with SEDS boost, and

- SEDS and storage to load.

These modes of operation are shown in Figure 3-3. It should be noted that the EDS energy input to load or storage can include a direct solar input from the collector field, an auxiliary heat input, or a combination of these two energy sources. The interface between EDS and SEDS will be an isolation heat exchanger (or a parallel set of exchangers when the solar input is separated into several collector subsystems), although the equipment will allow a direct connection between SEDS and storage or load, if desirable.

A heat exchanger interface between SEDS and EDS is required inasmuch as a heat transfer oil will probably be used in the collector field and pressurized water will be present in EDS. Table 3-1 lists the considerations that result in oil being a suitable fluid for the collector field in many instances. Fluid freeze protection would be required in Colorado if water were used.

The choice of pressurized water in EDS reflects the fact that steam delivery is a SERAPH goal, and many devices intended for solar applications (such as an absorption chiller) are designed to be powered by hot water. Freeze protection is not required because EDS is located entirely within the heated SERAPH equipment building. Steam generation can be accomplished directly via a throttling blowdown process of the EDS water combined with a separator. Indirect steam generation is also possible via an unfired package boiler which uses EDS hot water to boil a secondary water supply.

The conversion efficiency of the blowdown (flashing) steam generation process is shown in Figure $3-4$ as a function of 


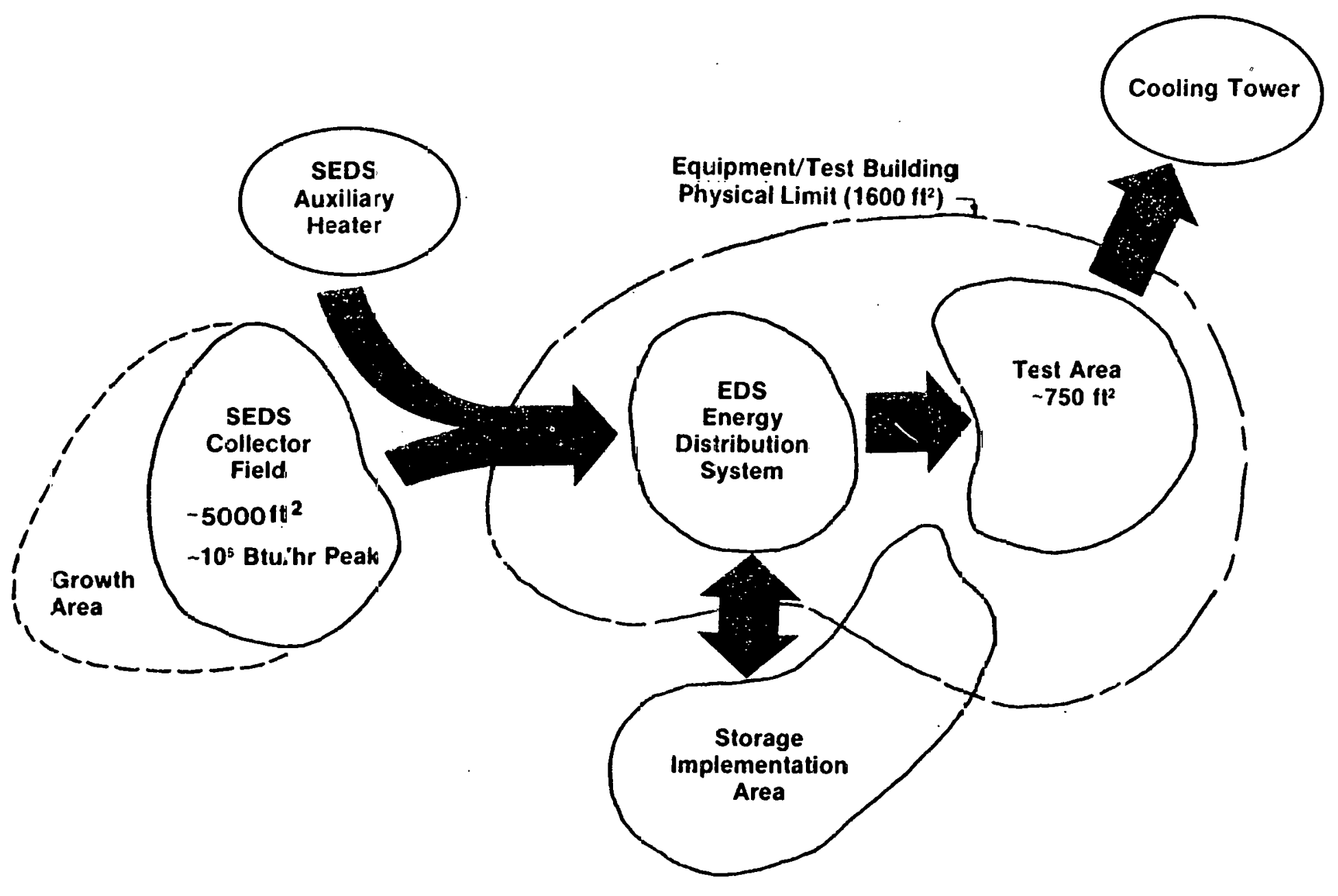

Figure 3-1. ENERGY FLOW IN SERAPH 


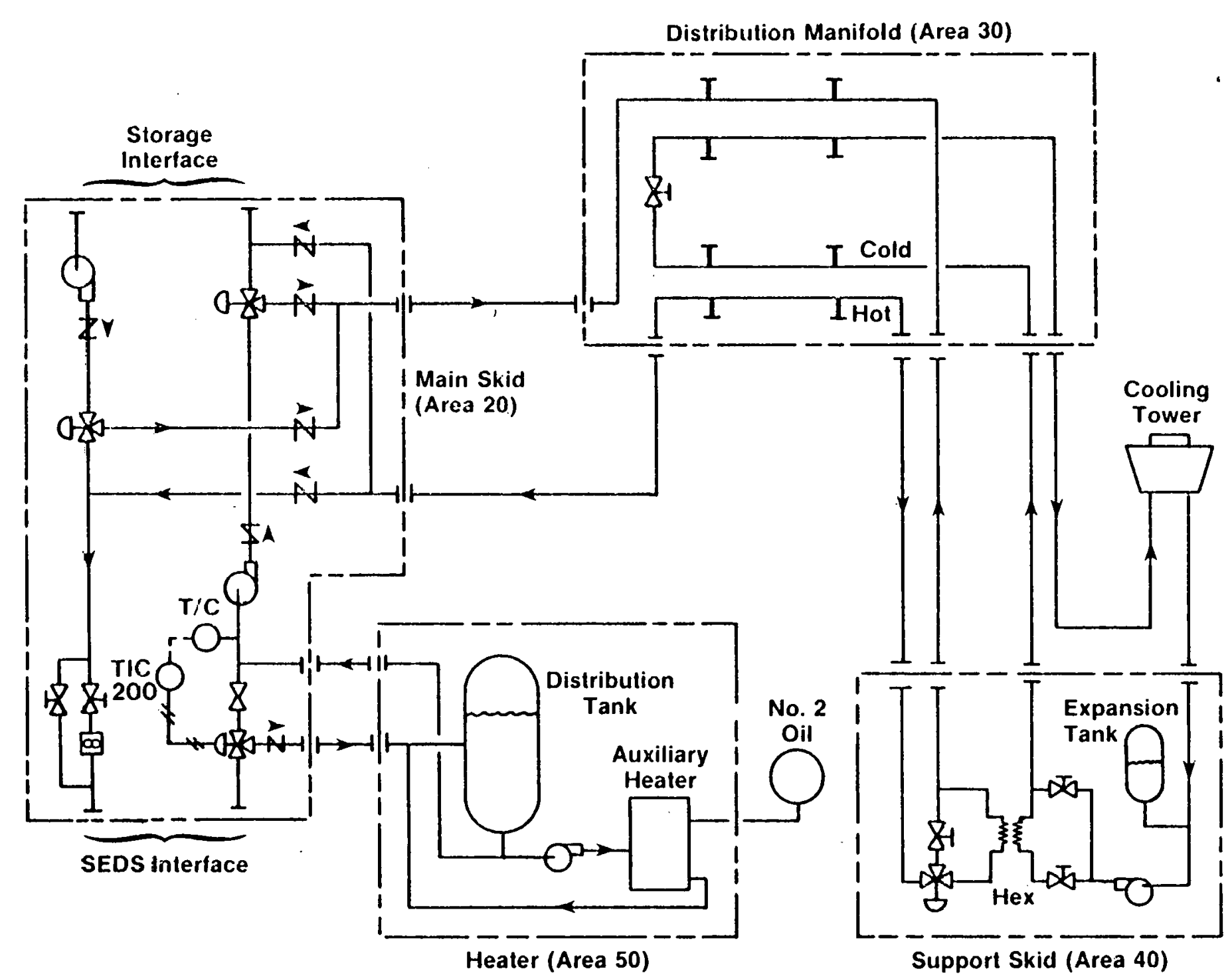

Figure 3-2. CONCEPTUAL LAYOUT FOR THE ENERGY DISTRIBUTION SYSTEM (EDS) 


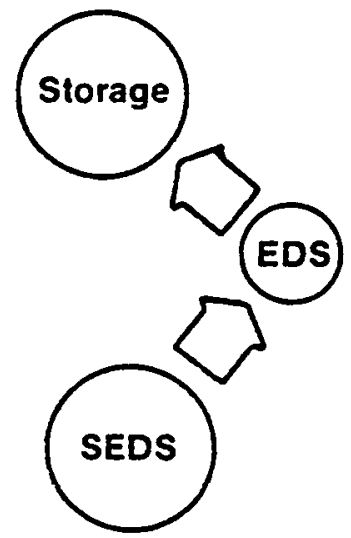

A. Field Oulpul lu Sluraye

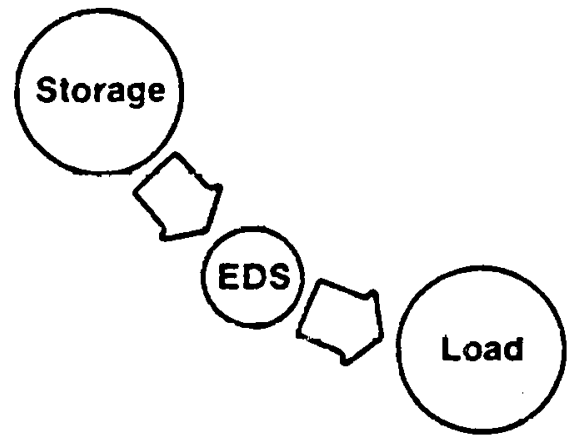

C. Stnrage to Load

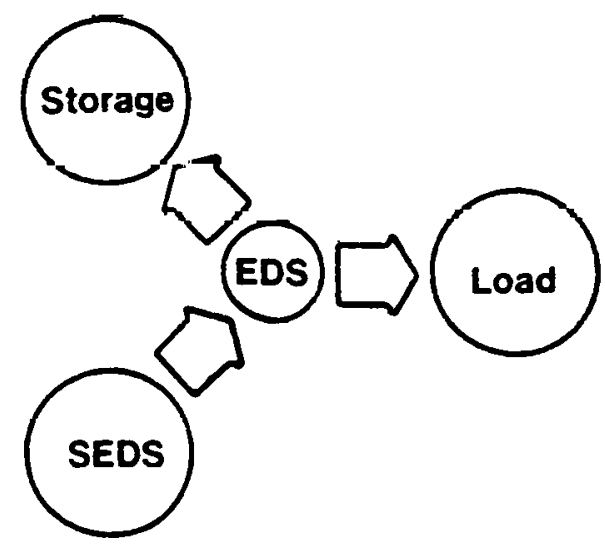

E. Field Output to Load and Storage

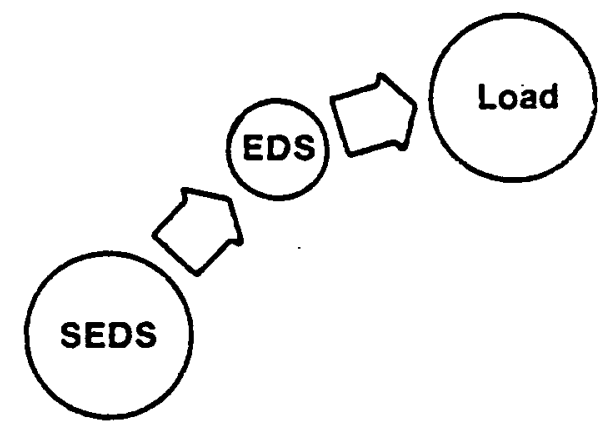

B. Fleld Uutput to Loảd

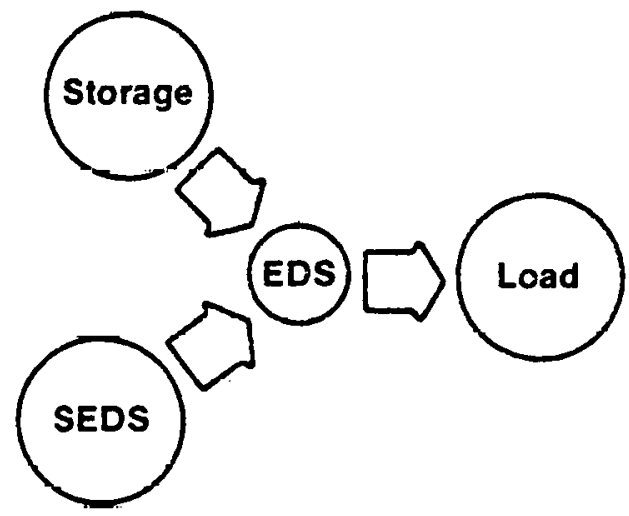

D. Field'Plue Storago to Luad

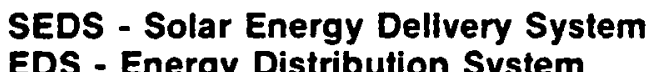




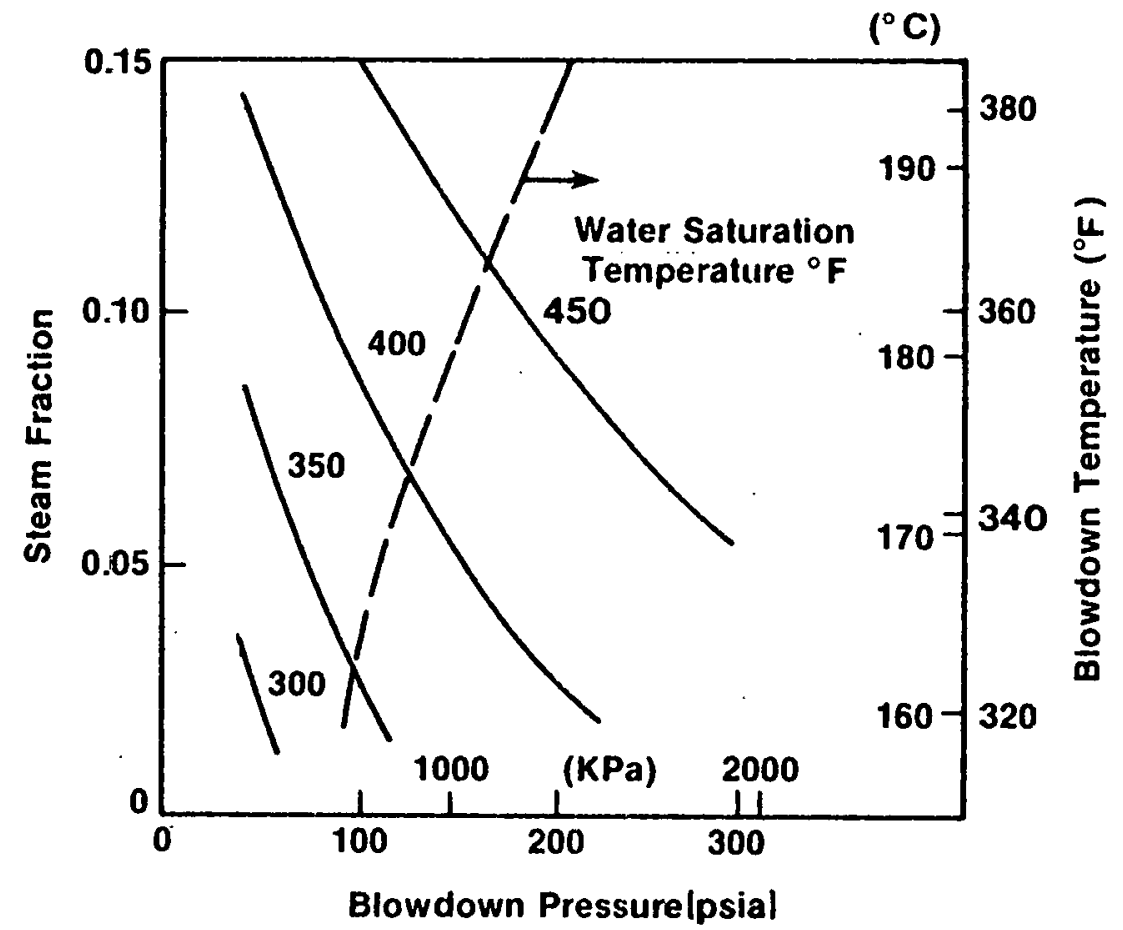

Figure 3-4. STEAM CONDITIONS RESULTING FROM FLASH BLOWDOWN 
Table 3-1. HEAT TRANSFER FLUID SELECTION ISSUES

- Fluid cost, anticipated lifetime, and disposal cost

- Sampling requirements to verify fluid quality

- Toxicity

- Flammability (flashpoint, fire point, auto-ignition temperature) and resultant electrical classification for surrounding areas

- Compatibility with other system materials (such as piping, packing and seals, valve seats, flex-hoses, and storage materials) as well as materials on to which it may leak (insulation, roofing)

- Physical properties

* freeze point

* viscosity at low (startup) and high (operating) temperature

* vapor pressure

* specific heat

* thermal conduc țivity

* density

- Availability of solvents or other cleanup materials

- Stability at operating temperature

- Potential vapor emíssions

the water supply saturation temperature and the steam delivery pressure. For example, at a water delivery temperature of $450^{\circ} \mathrm{F}\left(232^{\circ} \mathrm{C}\right), 12.5 \%$ of the water stream will flash to steam at 135 psia $(930 \mathrm{kPa})$ and $351^{\circ} \mathrm{F}\left(177^{\circ} \mathrm{C}\right)$. For a nominal SERAPH collector field size of $5000 \mathrm{ft}^{2}\left(464 \mathrm{~m}^{2}\right)$ the maximum steam delivery rate at these conditions would be approximately $900 \mathrm{lb} / \mathrm{h}$ (treated makeup water at this rate delivered at about 450 psia [3100 kPa] would be required if the steam were expended in the load).

The Department of Energy (DOE)-funded IPH project at the West Point Fepperell Mill in Fairfax, Ala., is an example of steám generution via an unfired package boiler, and the IPH project at the Johnson \& Johnson plant in Sherman, Tex., utilizes the blowdown approach to steam generation.

An important portion of EDS is the distribution manifold that delivers the hot water throughout the load area. It will be possible to move load devices into this area and to connect them directly to the overhead manifold. Nominal pressurized hot watcr delivery rate to the manifold will be $100 \mathrm{gpm}(380 \mathrm{l} / \mathrm{min})$. Figure 3-5 shows the placement of the major EDS items within the equipment building as wcll as thc routing of the hot water manifold. The presence of an nil-fired auxiliary heater should be noted in EDS. Thls heater is included to allow equipment operation during periods of low solar input. The heater serves a secondary purpose: preclse temperature control of the hot water being used in the load area. A third capability is programming of the auxiliary heater output to simulate the transient energy delivery characteristic of a collector field at an arbitrary geographical location (see Section 6.0).

Another important component in EDS is 


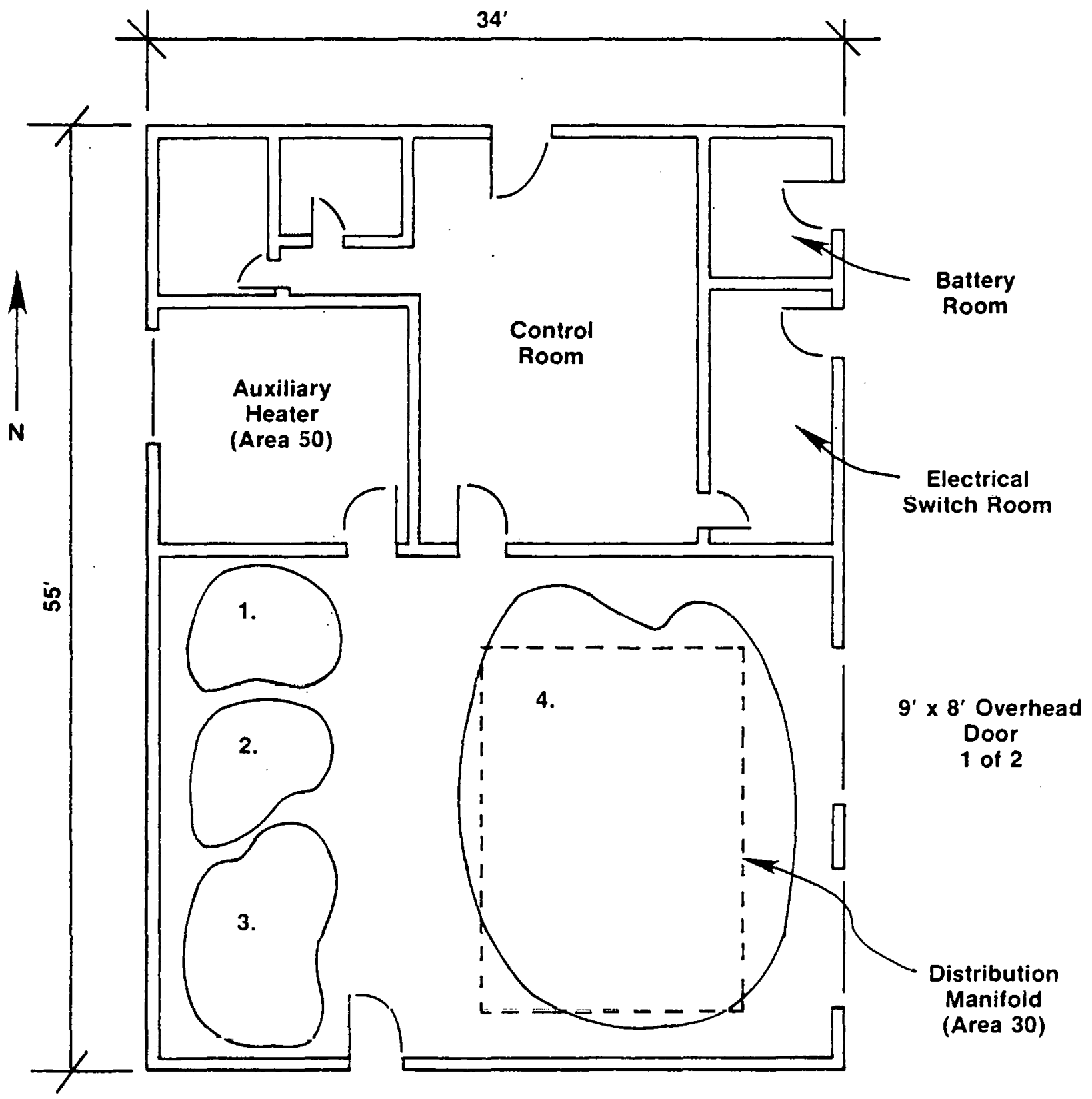

Location: 1. Storage Hook-Up Equipment

2. EDS Equipment (Area 20)

3. SEDS Support Equipment

4. Load Aroa

Figure 3-5. SOLAR EQUIPMENT BUILDING 
the load heat exchanger shown in Figure 3-2 (Area 40). This unit is included as a means to simulate the load demand characteristic of individual industrial processes. By modulating the flow of hot water in the heat exchanger the net energy extraction rate from EDS can be made to follow a predetermined, timedependent profile. Under these conditions it will be of interest to evaluate the extent to which SEDS (with help from the auxiliary heater and thermal storage if so desired) is able to maintain suitable energy supply conditions in terms of temperature and flow rate. Energy is deposited in a cold water/glycol stream which transfers it for rejection to the atmosphere in the cooling tower.

A major consideration in the selection of an EDS layout is the separation of its components into functional areas as shown in Figure 3-2. The energy routing portion (Area 20), auxiliary heat addition (Area 50), heat rejection and load simulation (Area 40), and the test manifold (Area 30) all are physically separated to emphasize their functional differences. All of these areas in turn are isolated from the storage connection and development function (Area 60) and the Solar Energy Delivery Subsystem (SEDS, Area 10). This approach is taken so that potential industrial solar system users are not confounded by the overall extent of SERAPH. Functional separation permits a visitor to appreciate the type and magnitude of components that may be required in his installation while excluding SERAPH items that may be present solely for research reasons. This philosophy will carry over to the layout of equipment in the Control Room as well. 


\section{SECTION 4.0}

\section{THE SOLAR INPUT}

The Solar Energy Delivery Subsystem (SEDS) will provide energy input to the balance of the SERAPH facility with the transient startup, operating, and shutdown characteristics that must be addressed in the operation of any industrial solar system. Selection of the solar system establishes the energy handling requirements for the balance of SERAPH and, hence, has a first order impact on overall facility size, component testing capability, and cost.

The collector field nominal minimum daily energy delivery will be approximately $3.0 \times 10^{6} \mathrm{Btu}\left(3.2 \times 10^{6} \mathrm{~kJ}\right)$. This requirem ent should result in a net collector field aperture of approximately 5000 $\mathrm{ft}^{2}\left(460 \mathrm{~m}^{2}\right)$. This field size is large enough to identify and resolve many collector array problems (manifolding and flow control, piping, thermal and pumping losses, multiple row tracking, startup, shutdown, emergency action, etc.). It is anticipated that one, two, or three types of line concentrators will constitute the initial field. If more than one model of concentrator were selected, each model would be incorporated into an independent SEDS complete with its own circulating pump and set of controls. Each SEDS would interface with the Energy Distribution Subsystem (EDS) through a eeparate heat exchanger.

Provisions and space will exist for future expansion of the collector field to accommodate the addition of collectors for increasing the solar energy input or for substituting other types of concentrating collectors. Additions may be in the form of east-west or north-south collector rows as well as discrete units (such as parabolic dishes) or a small-scale line focus power tower. Future increases in solar energy input may take place through an existing SEDS or bypass it altogether via a direct connection to EDS.

Two fluid flow control modes will be present in SEDS: flow may be modulated to achieve a desired water output temperature set point, or flow may be held constant so that the output temperature varies throughout the day. The latter approach enables the collectors to deliver energy at temperature levels below the process temperature requirement, thereby providing a useful preheating fraction when insolation conditions preclude satisfying the process temperature requirement. Section $\mathbf{8 . 2}$ discusses the SERAPH process control functions in greater detail.

Collector field control actions, initially maintained by analog controllers, will be amenable to direct digital control (DDC) and supervisory control. This adaptation feature looks forward to the situation in which a microprocessor will be used to implement a series of control strategies or to the need for sequential test conditions when evaluating solar equipment. Control actions primarily consist of modulating fluid flow and positioning of collector arrays.

Industrial surveys indicate that a large energy demand exists below $392^{\circ} \mathrm{F}$ $\left(200^{\circ} \mathrm{C}\right)$. SEDS will be capable of delivering energy to the EDS at temperature levels up to $430^{\circ} \mathrm{F}\left(220^{\circ} \mathrm{C}\right)$. This peak temperature encompasses conditions present in the most recent round of DOE-funded industrial process heat pro- 
jects (FY78, see Table 4-1). The maximum operating pressure in EDS, charged with chemically treated water, will be approximately 450 psig $(3,050 \mathrm{kPa})$. Higher temperatures that result in a rapidly increasing saturation pressure would increase the system cost significantly. In addition, the validation and. updating of analytic models (a primary SERAPH goal) does not require that operating temperatures be pushed to the maximum value. It will be possible to connect SEDS directly with a load or storage device compatible with the SEDS fluid conditions. This action would circumvent the temperature loss penalty associated with the EDS interface heat exchanger if a heat transfer oil were used in SEDS. Such a direct connection would result in energy delivery by SEDS at temperatures to approximately $600^{\circ} \mathrm{F}$ $\left(315^{\circ} \mathrm{C}\right)$.

SEDS will be procured as a package complete with all controls and an interface heat exchanger to permit energy transfer. to EDS. The procurement specification will be written around the nominal minimum daily energy delivery at the maximum operating temperature, with local insolation and temperature conditions specified. This procurement approach is intended to model a technique which may be favored by industry. The designer is given freedom in selecting system components as long as a minimum amount of energy is provided at a specified temperat ure.
Figure 4-1 identifies the space set aside for the collector field and Figure 3-5 shows the positioning of the balance of the SEDS equipment within the equipment building. The collector field area slopes to the southeast with a gradient of approximately $3 \%$. Apprnximately $17,500 \mathrm{ft}^{2}\left(1620 \mathrm{~m}^{2}\right)$ have been set aside for the $5000 \mathrm{ft}^{2}\left(460 \mathrm{~m}^{2}\right)$ collector field. The SERAPH site includes at least $25,000 \mathrm{ft}^{2}\left(231.5 \mathrm{~m}^{2}\right)$ of additional open space available for expansion of the solar collection function.

A $5000 \mathrm{ft}^{2}\left(460 \mathrm{~m}^{2}\right)$ collector field would have a nominal daily energy delivery of at least 3.0 million $\mathrm{Btu}$ in the winter months and higher summer outputs.

Figure 4-2 shows components in the SEDS piping and instrumentation diagram. Evaluation of SEDS requires accurate transducers for monitoring temperature, pressure, collector position, and flow rate within SEDS. Fignure 4-2 describes the locations where SERI will be able to introduce detectors to monitor total fluid flow, individual collector row flow, collector row temperature rise and temperature loss across the interface heat exchanger. These detectors will be independent of those used for control purposes. Shaft encoders will be present on each collector row to provide a rotational position signal. 
Table 4-1. RECENT DOE INDUSTRIAL PROCESS HEAT STEAM AW ARDS ${ }^{\mathbb{a}}$ (SEPTEMBER/OCTOBER 1978)

\begin{tabular}{lcr}
\hline \multicolumn{1}{c}{ Design Firm } & $\begin{array}{c}\text { Saturated Steam } \\
\text { Temperature }\left({ }^{\circ} \mathrm{F}\right)\end{array}$ & $\begin{array}{c}\text { Field Size } \\
\left(\mathrm{ft}^{2}\right)\end{array}$ \\
\hline Acurex Corp. & 365 & 20,000 \\
Foster-Wheeler & 366 & 10,000 \\
Jacobs Del Solar Systems & 366 & 15,000 \\
Monum ent Solar Corp. & 380 & 9,600 \\
Southwest Research Inst. & 351 & 10,300 \\
Stauffer Chemical Co. & 368 & 9,300 \\
TRW & 417 & 10,000 \\
\hline
\end{tabular}

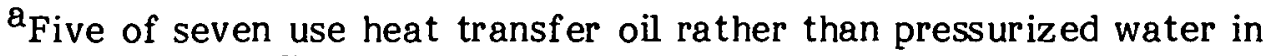
the collector field. 


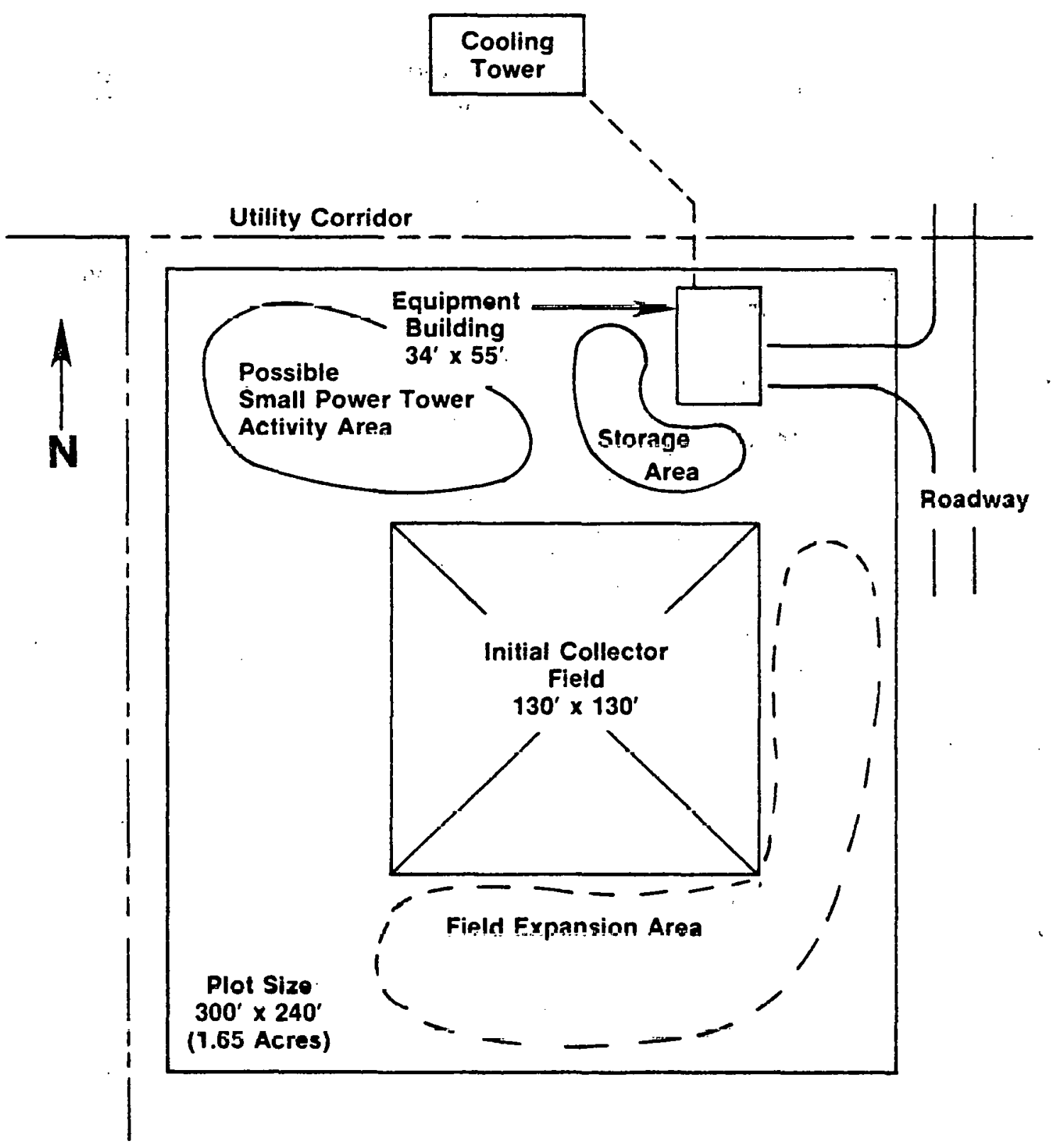

Figure 4-1. SERAPH FIELD TEST SITE LAYOUT 


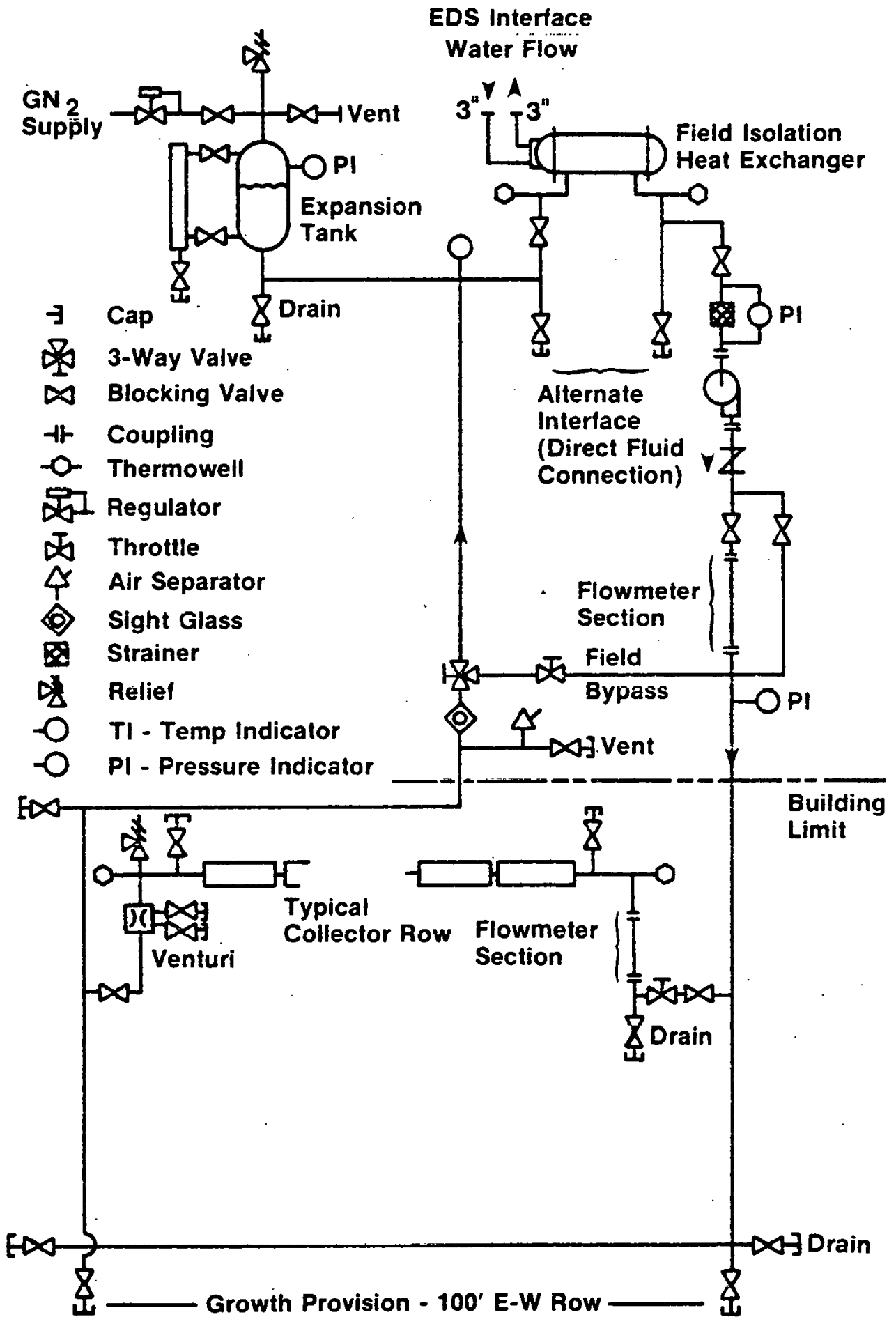

Figure 4-2. SEDS PROCESS DIAGRAM 
THIS PAGE INTENTIONALLY LEFT BLANK 


\section{SECTION 5.0}

\section{ENERGY STORAGE}

The solar IPH systems most attractive from an economic viewpoint do not include energy storage provisions unless an existing onsite storage device can be utilized. Current IPH solar systems operate in a fuel displacement mode, and the entire solar output is expended as generated-typically in a comparatively large load. As storage devices do come on-line, they will probably be cycled on a short term basis, providing capacity comparable to only a few hours of solar output at peak conditions. Capacity will increase as more cost-effective storage concepts are demonstrated.

In its initial form, SERAPH will not contain energy storage provisions. Instead, means will be provided to couple storage devices as they become attractive for industrial applications. When the solar input exceeds immediate load demand in SERAPH, the excess energy will be dissipated directly in the cooling system. It is anticipated that storage concepts that have performed well on a small scale in the laboratory will be implemented on a larger scale in SERAPH. Performance of the installed device will be monitored in response to an actual collector field input and industrial load environment.
Storage units may be erected inside or outside the equipment building. Figure 3-3 indicates the operational modes involving storage that can be exercised by the Energy Distribution Subsystem (EDS). It will also be possible to make a direct connection between the collector field fluid circuit and the storage device (bypassing EDS) with a second connection to load (through or around EDS). This action may be taken if the temperature limitations of EDS provide an unnecessary restriction on system testing of the particular storage device.

A potential storage concept that may be evaluated first at SERAPH is the sensible heat buffer concept. The buffer system consists of a fluid storage tank sized to maintain uninterrupted energy delivery to the load during short periods (5-15 min) when cloud activity may cut off the collector field output. This function can be acquired at a modest cost compared to single or multiple day thermal storage and can minimize cycling of the backup energy source. 
THIS PAGE INTENTIONALLY LEFT BLANK 


\section{SECTION 6.0}

\section{COLLECTOR FIELD EXPERIMENTAL SIMULATION}

To compare the performance of alternative solar-powered IPH equipment, it is prudent to conduct performance tests with identical solar input. Because insolation varies from day to day due to weather or solar position, it is necessary to be able to simulate, in a repetitive fashion, the output of the collector field. It is also of interest to quantify the shif ts in equipment performance in response to solar inputs from differing geographical locations.

An experimentally simulated collector field output would permit such an evaluation. Collector field output simulation in SERAPH will be accomplished by using the auxiliary heater. The output of the heater would be controlled by a computer model of solar insolation and collector field response which delivers a signal proportional to the outlet temperature of the collector field.

One method of simulating the collector field output can be described by reference to Figure 3-2. Fluid flow in the collector field (SEDS) is terminated during this operation and the collectors are stowed. A computer model of the collector delivers a time varying set-point signal to the controller ( $\mathrm{TIC} / 200$ ) in Area 20 of EDS; the signal is proportional to the computed outlet temperature of the collector field. As input the computer model will use the condition of the fluid entering the field, the selected insolation and ambient temperature conditions, physical characteristics of the collector field, and control strategy.
Model calculations either may be completed before initiating the test or carried out on a real-time basis. The primary EDS flow splits into two branches. One branch flows through the distribution tank (Area 50) and one branch bypasses the tank. Flows passing through each branch are blended under the command of the controller to produce an output stream with the desired temperature. The conventional auxiliary heater controller maintains suitable temperature conditions in the distribution tank. The transient response of this proposed collector field simulator would need to be of the same order as that of the field. A time constant of approximately $30 \mathrm{~s}$ should be representative and achievable.

The sophistication of the model used to calculate the collector output temperature is dependent upon the degree of accuracy required. Simple steady-state models such as those in the TRNSYS and SOLTES libraries are adequate if it is sufficient to predict the average flow rate and outlet temperature over a relatively long period of time $[4,5]$. In reality, these actual flow rates and temperatures may not even occur over the time step. Insolation values will change rapidly as the sun is blocked by a cloud, resulting in large changes in either outlet temperature or flow rate. With on/off control, low insolation values may result in pump cycling.

To learn more about system response to such transient conditions, a more com- 
plex collector field model must be used. Such a model has been developed at SERI. This method solves a set of partial differential equations that account for the variation of fluid temperature with both time and position. 


\section{SECTION 7.0}

\section{SERAPH MODELING}

The purpose of the modeling effort is to develop a transient model of SERAPH operation that will apply to other IPH configurations. Such a system will be useful in:

- evaluating new IPH system configurations;

- optimizing the design and operating conditions of proposed installations;

- comparing competing control strategies, selecting control parameters (gain, reset rate); and

- identifying solutions to operating problems in new installations.

The development of such a modeling system is given the highest priority in the DOE Solar Heating and Cooling $R \& D$ Plan.

Initially the model will be used at SERI to judge SERAPH performance prior to system operation. Tasks that would be aided by the progrum include choice of operating parameters, choice of control strategies, and selection of new operating modes.

As SERAPH becomes operational, model output will bc compared with actual system operating data. Component models will be fine-tuned and the modeling method validated. As more component models are validated, the method will become applicable to facilities other than SERAPH. At that time it is expected that the code would become widely used as an analysis tool for pro- cess heat applications in the same manner that TRNSYS is now used for residential studies.

The SERAPH system model code will complement existing SERI process heat codes such as PROSYS but will operate on a time scale and level of detail much finer than that of PROSYS [6]. Hence, while it will be ideally suited to process simulation work, it will be too detailed and time consuming for ready application to end-use matching studies.

To provide the flexibility necessary to model many different systems, the code must be of the modular type. Components such as collectors, storage, controls, and conversion devices will be modeled separately, allowing the user to specify the desired arrangement. An executive program will control information flow between the models, solve the set of simultaneous equations which describe the system, and handle input and output control.

The executive program will be SOLTES1, an energy system simulation program developed by Sandia Albuquerque Laboratories [5]. Component models will be adapted from the SOLTES and TRNSYS libraries, as well as from the work of individual researchers.

Input to the program is of two types: the specification of hardware, layout, and control strategy; and the application of the time-varying forcing functions that drive the energy supply system. In the case of SERAPH, these consist of insolation and load data as a function of time. With this information SOLTES co- 
ordinates the individual models to simulate system performance.

SOLTES will print on demand the state variables and fluid flow rate for the output of any system component, as well as system performance information such as integrated energy consumption or system efficiency. If detailed information about the conditions within a component are required, output commands must be inserted in to the component routine.

During FY80 it is planned to validate the model by comparing it with SERAPH operating data and to use the model to identify promising new operating modes and hardware configurations for the SERAPH facility. As the instrumentation at the SERAPH site collects meteorological data and the load is determined by the experimenter, both SERAPH and tho computer model may be subjected to identical forcing functions. In this manner, the results of SOLTES may be compared to relevant experimental data. As the model is perfected and validated, an increasing amount of confidence may be placed in its predictions. 


\section{SECTION 8.0}

\section{CONTROL AND DATA ACQUISITION SUBSYSTEMS}

The SERAPH control and data acquisition subsystems will accomplish the following objectives:

- ensure reliable, accurate, and stabilized process control;

- initiate emergency setback or shutdown;

- meet data acquisition requirements;

- enable development of new control methods and strategies;

- enable development of prototype control modules;

- enable establishment of standard and reliable control methods acceptable to potential industrial users;

- support simulation control requirements; and

- provide flexibility for configuration changes.

\subsection{CONTROL SUBSYSTEMS}

'The SERAPH farility and components will follow predetermined but changeable operating proccdurc for normal startup and shutdown, steady state operation, and emergency setback or shutdown. Consequently, the SERAPH operation will require automatic controls with provisions for manual override. Automatic controls will normally include analog, supervisory, and direct digital control schemes. Advanced control methods such as optimal control, predictive and adaptive control, feed forward control, load simulation, nonlinear modeling, etc., will be exercised when the control algorithms are developed.

A typical operating procedure will include:

- manual operation to permit checkout and function testing of components,

- automatic analog controls to be implemented following successful manual operation, and

- fully automatic operation by use of supervisory or direct digital control when enough control experience is gained.

Failure mode operations will include the following as a minimum:

- the controllers will hold in the last position or go to a safe position;

- the final control elements such as control valves will go to a safe position;

- the collectors will take corrective or defocus actions as requirer;

- provisions will be made for alarming prior to shutdown; and

- emergency shutdown circuits will be fail-safe designed. 
Basically, the SERAPH facility will include measurements for control purposes and precision measurements for data acquisition or testing purposes. Where practical, these two types of measurements will use separate sensing elements. Research-oriented monitoring functions require precision measurements, with high accuracy the most important consideration. Due to anticipated changing requirements, installation practice will be flexible to enable easy replacement of the sensing element. Adequate measurements also are required for established reliable process control. Rellabllity and áceuracy are both critical considerations. Industrial grade, high-quality sensing elements will be used.

\subsubsection{Analog Control}

In order to accommodate the experimental nature of the facility and to achieve reliable and flexible process control, the SERAPH facility will utilize both analog and direct digital controllers (DDC). Figure 8-1 depicts the block diagram for a typical control loop. 'l'he analog controllers will operate in parallel with the DDC controllers. Advantages of this parallel arrangement include the fact that it:

- permits independent operations between DDC and analog control modes,

- provides supervisory control capability,

- permits wide selection of analog controllers,

- provides backup capability,
- permits a simple interface between control instruments,

- maintains analog control loop integrity,

- permits checkout and function testing without interfacing with the DDC controller, and

- provides a simple means to gain control experience for the supervisory or DDC control.

Conventional solid state electronic ana$\log$ controllers will be used for general analog controls. Typical operating modes will include:

- automatic control ("A") and local set-point ("L") mode,

- automatic control ("A") and remote set-point. ("R.") morie, and

- manual control mode ("M").

A conventional indicating deviation controller, whether implemented by anklog or digital circuitry, will provide automatic control actions including proportional only $(\mathrm{P})$, proportional plus integral (PI), proportional plus derivative (PD), or proportional plus integral plus derivative (PID) depending on specific requirements. The controllers will be the bumpless type. Set-point values will be monitored by the satellite CPU if required. When a special circuitry is used to perform a specific function not available in a conventional controller, a compatible interface with other instruments will be emphasized. This is often the case for collector tracking. 


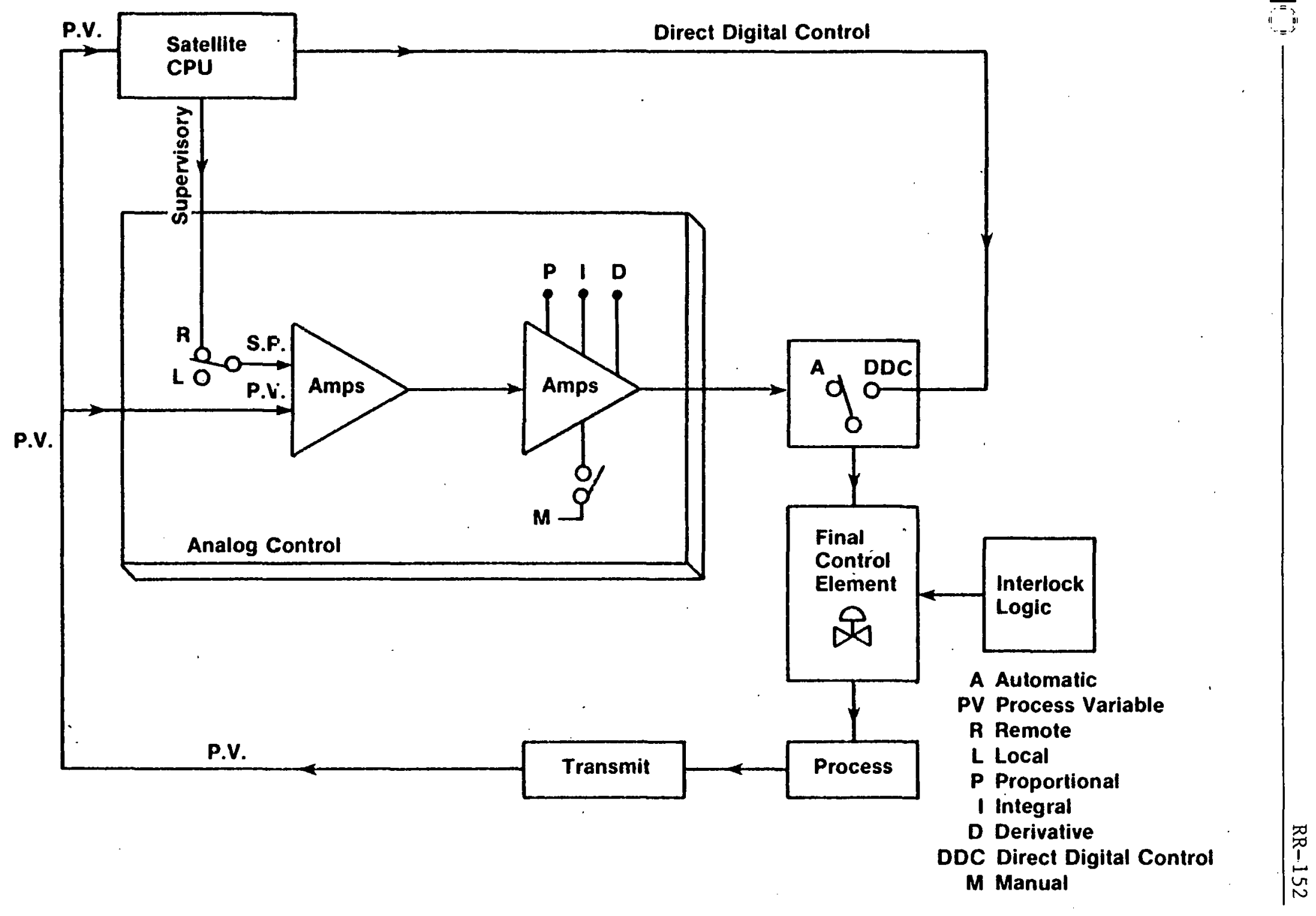

Figure 8-1. TYPICAL CONTROL LOOP 


\subsubsection{Supervisory Control}

Supervisory control will be activated by operating the analog controllers in the "A" (auto) and "R" (remote) modes. The set point will be adjusted from the satellite CPU. Supervisory control will enable operator-initiated set-point change, preprogrammed set-point adjustment, or computer set-point adjustment. Supervisory control will also permit closed-loop control, optimal control, and other advanced control methods by manipulating the set point values.

Supervisory set point will be full-value type, normally in the form of 420 mAd.c. To ensure reliable supervisory control, the I/O modules of the satellite CPU will include the sample-and-hold features to hold the set point in the last position.

\subsubsection{Direet Digital Control (DDC)}

When the SERAPH facility operates in the direct digital control (DDC) mode, the satellite CPU will monitor process variables, perform necessary control computations or manipulations according to the control algorithms developed, and then initiate an output signal directly to the control elements. The output signals preferably will be full value 4-20 mAd.c for throttling control. For on/off controls, contact closures will provide simple interfaces. Other types of signals will be used depending on specific requirements.

The DDC control is a highly flexible scheme in the sense that only software reprogramming plus minimal hardware changes will be required for adapting to reconfigurations. The DDC controllers will be capable of proportional, integral, derivative, and deviation controls, and in addition can practice advanced control strategies including:

- closed loop control,

- feedback control,

- predictive or feedforward control,

- adaptive control,

- optimal control,

- nonlinear control, and

- simulations.

As a testing facility, SERAPH will experience a variety of reconfigurations and test programs. When successfully implemented, the DDC will become a highly useful tool for the SERAPH applications.

\subsubsection{Sequencing and Shutdown Logic Control}

The SERAPH facility will experience a variety of discrete sequencing and interlock logic controls. Sequencing is important because it provides a means for ensuring that certain predetermined conditions exist prior to mitigating some action. For cxample, fluid flow through the auxiliary heater must be present hefore the main burner is lighted. A stand-alone programmable logic controller (PLC) will be highly suited to the changing nature of the SERAPH facility, as the PLC can be reprogrammed easily and can provide compatible interfaces with other controls. There is a possibility that the satellite CPU can be programmed to perform the sequencing 
logic controls. However, in order to achieve highly reliable controls, the PLC and satellite CPU should be kept functionally separate.

When the process and sequencing logic controllers fail to confine the process within safety limits, the emergency shutdown (ESD) subsystem will operate. The ESD system will be fail-safe designed.

\subsection{DATA ACQUISITION SYSTEMS}

The SERAPH data acquisition subsystems will be part of the entire SERI Laboratory and Field Data Management System. As a minimum, the SERAPH data management functions will:

- acquire sufficient test data to describe component and system characteristic behavior,

- provide adequate data archiving and processing capability for performing small-scale analysis tasks,

- enable development of control algorithms based on data acquired, and

- provide supervisory control and direct digital control capabilities as required.

\subsubsection{Central Data System}

The SERI Research Division central data system will be a distributed data processing (DDP) system (Figure 8-2) with the following main components:

- laboratory host CPU and associated peripherals,
- telecommunications subsystem,

- laboratory terminals, and

- Field Test Site data subsystem.

The laboratory host CPU is the hub of the SERI Research Division central data subsystem. Main functions of the laboratory host CPU and peripherals are to:

- përform real-time data acquisition and limited instrument control for several experiments simultaneously;

- support local intelligence (intelligent terminals, microcomputers, and minicomputers) by providing a variety of peripherals, such as disk and tape mass storage, line printer, and digital plotter;

- provide computing power adequate for quick turnaround data analysis;

- sustain analytical databases together with the necessary management system;

- possess an operating subsystem which provides complete memory protection between users; and

- contain multiple levels of both hardware and sof tware priorities.

\subsubsection{Field Test Site Data Subsystem}

The Field Test Site is designed to support both short- and long-term test operations. SERAPH is one of these operations. The test site data subsystem is functionally a duplicate of the laboratory host data system, but on a smaller scale. The laboratory host system can 


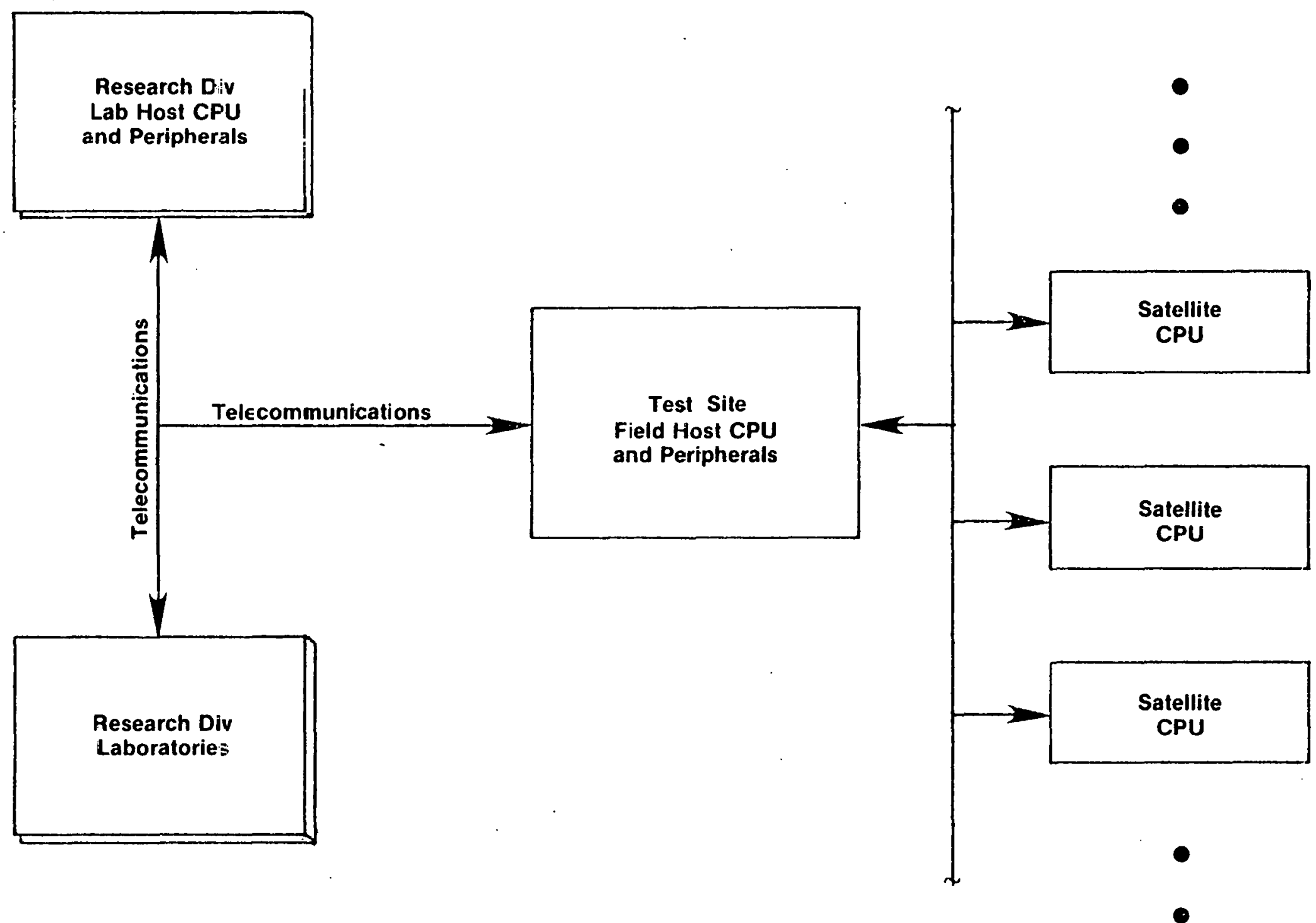


monitor and control the activities of the field host. In the event of a test site CPU failure, the duties of this computer can be taken over by the laboratory host CPU. Prior to delivery of the laboratory host CPU the test site data subsystem will exercise all digital control and data acquisition responsibilities.

The Field Test Site data subsystem shown in Figure 8-3 will perform the following main functions:

- acquire data from instrumentation to be employed in control subsystems and analysis;

- provide digital and analog control to the systems under test;

- process, store, and display acquired data (real-time and historical data); and

- allow branch personnel to monitor and control test performance remotely from the main SERI laboratory as well as at the Field Site.

It is planned that the SERAPH facility will use two satellite CPU subsystems: one for data acquisition and the other for computer control of processes. A temporary arrangement of each satellite CPU subsystem is shown in Figure 8-4. A final configuration may include only the satellite CPU and a transportable terminal for man/machine interface. The satellite CPU system functions will be to:

- perform data acquisition and automatic control,

- allow quick replacement if failure occurs,
- develop control algorithms from experiment parameter table,

- communicate to field host CPU periodically,

- continue control when field host CPU fails, and

- have local display and control through a transportable terminal.

\subsection{DEVELOPMENT $\Lambda$ ND IMPACT}

Because the SERAPH facility will be used for a variety of test programs, the control and data acquisition subsystems will accommodate different types of test equipment such as collectors, heat exchangers, heaters, chillers, rotating machinery, etc. The reprogramming capabilities of the microcomputer-based system chosen for the SERAPH facility will meet these requirements.

The SERAPH facility will allow for growth, including storage devices, new collector types, etc. To meet these requirements, the control and data acquisition subsystem will be capable of hardware and software expansion, such as additional memory cards, computer peripherals, controllers, etc.

Simulations of industrial energy utilization will be part of the SERAPH programs. The control system will be programmed to control associated process parameters versus certain variables for industrial load simulators. The control subsystem will also be programmed to control a certain process in order to simulate an energy delivery system located in a specific geographical area. The experimental data should provide the 


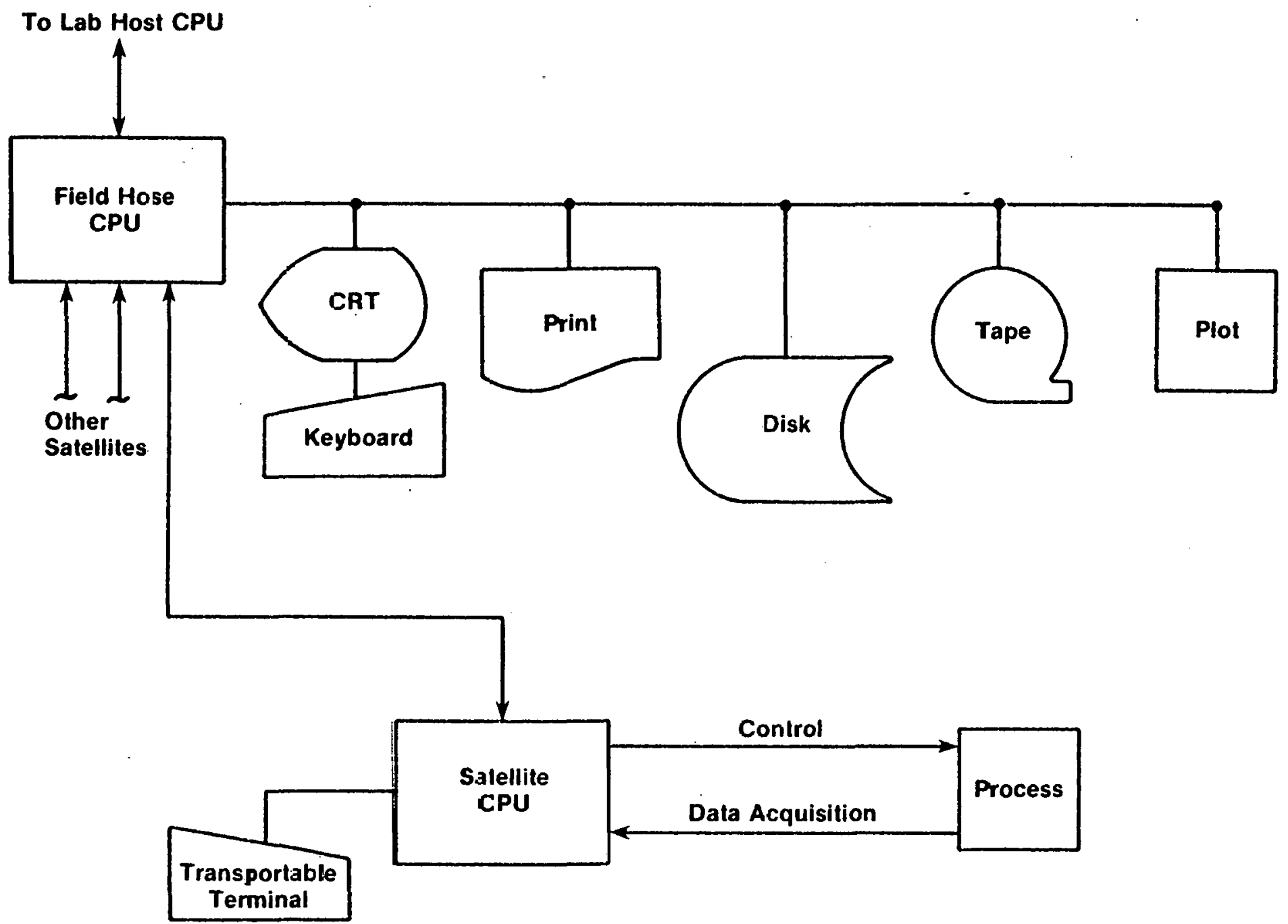

Figure 8-3. FIELD TEST SITE DATA SYSTEM 


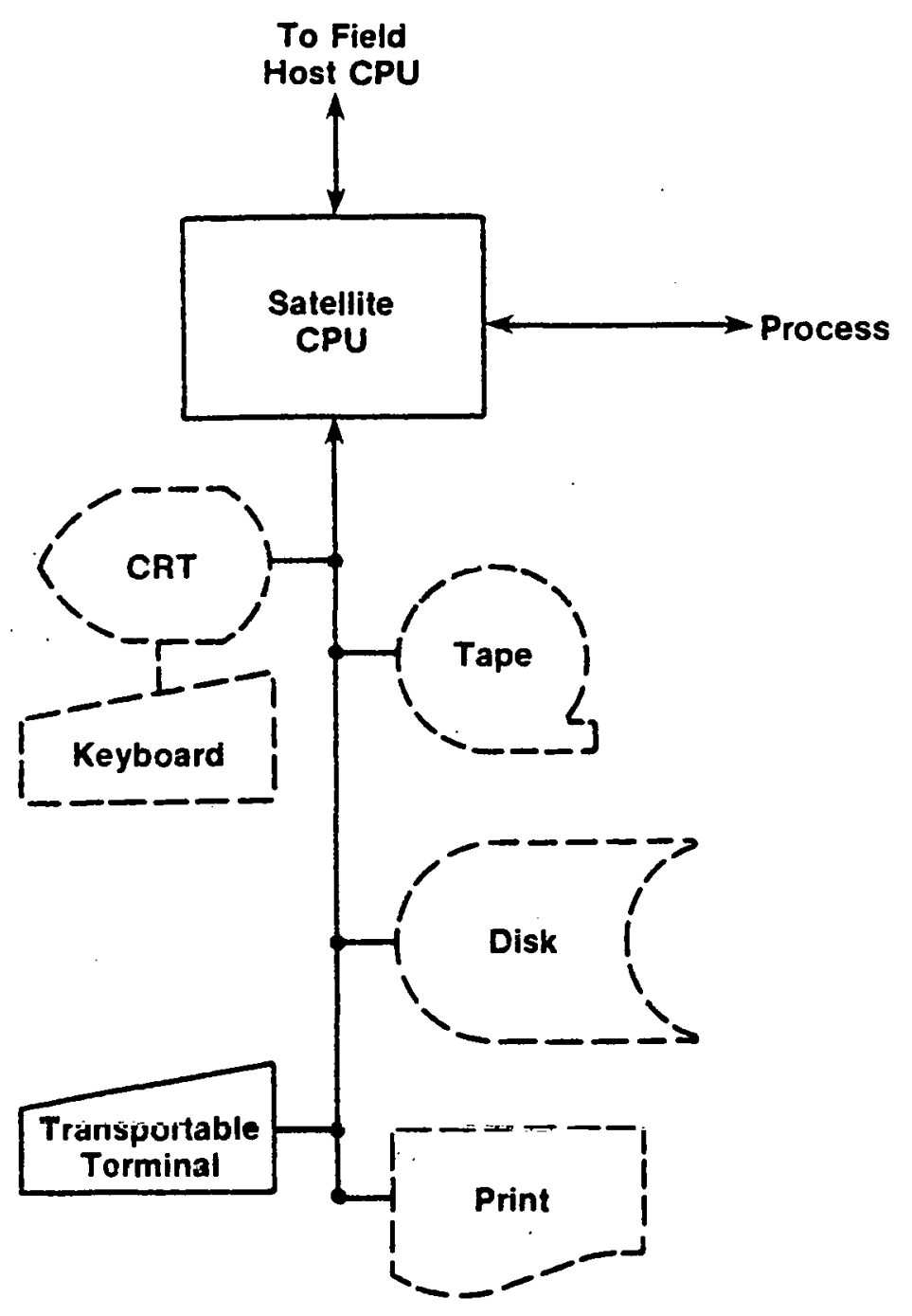

Figure 8-4, SATELLITE CPU 
basis for development of system analytic models which will be validated by the control system.

It is expected that the control subsystem will exercise advanced control strategies as the test program continues. There will be a variety of advanced control schemes as outlined in Section 8.1. Each will need specific definition, development, and experience before meaningful experiments can be done. The microcomputer-based subsystem will adapt readily to new control schemes with minimal changes or modifications. An immediate experiment will be the implementation of the computerized sun position tracking to set the feedforward control circuitry for collector tracking. This experiment will enable comparisons between the direct sun-sensing method and the computerized method.

Evaluation of control strategies will be based on subsystem performance and cost-effectiveness. Performance evaluation will depend on the subsystem reliability, stability, flexibility, simplicity, accuracy, and life. Cost-effectiveness will determine the justification for development. Commercial availability and industrial quality of the components will also be important considerations.

The SERAPH control subsystem and data acquisition equipment should aim at accomplishing certain goals:

- developing control guidelines;

- incorporating advanced control schemes in to simpler devices;

- using experimental results to provide feedback to vendors for product improvement or new development;

- making control methods developed acceptable to potential industrial users;

- recommending revisions in existing codes, regulations, and standards to adapt them to solar systems; and

- developing new standards. 


\section{SECTION 9.0}

\section{COMMERCIAL CHILLER EVALUATION}

One of the potential first uses of the SERAPH facility is the testing of solarpowered chillers. Ranging in capacity from 3 to 75 tons, these units are being developed under Department of Energy funding at Arkla Industries, Honeywell, and Carrier Corporation. Absorption and Rankine cycle-powered units are under development. SERAPH's size is such that it would be readily compatible with chillers having ratings in the range of 15 to 25 tons - units intended for commercial operation.

A chiller would be incorporated into SERAPH for test as shown in Figure 9-1. Solar-heated hot water delivered by the Energy Distribution Subsystem (EDS) is supplied to the generator of an absorption unit or to the boiler section in a Rankine-powered unit. The hot water is also used to create a load condition through an isolating heat exchanger on the load side of the chiller. The required hot water temperature would be $150^{\circ}$ to $250^{\circ} \mathrm{F}\left(66^{\circ}\right.$ to $\left.121^{\circ} \mathrm{C}\right)$. Heat rejection is accomplished at the cooling tower in SERAPH. Circulating cold water is provided at the condensor section of the chiller and would normally be capable of rejecting energy at the rate of approximately $800 \mathrm{MBtu} / \mathrm{h}(235 \mathrm{~kW})$ at $85^{\circ} \mathrm{F}\left(29^{\circ} \mathrm{C}\right)$.

Air conditioning units are generally rated by their manufacturers at a single operating point. For example, the rated capacity of the Arkla Solaire 300 $\mathrm{H}_{2} \mathrm{O}-\mathrm{LiBr}$ absorption chiller is 25.5 tons with a coefficient of performance (COP) of 0.72 when the generator inlet water temperature is $195^{\circ} \mathrm{F}\left(90^{\circ} \mathrm{C}\right)$, the con- denser inlet water temperature is $85^{\circ} \mathrm{F}$ $\left(29^{\circ} \mathrm{C}\right)$, and the chilled water outlet temperature is $45^{\circ} \mathrm{F}\left(7^{\circ} \mathrm{C}\right)$. Due to the variable nature of solar energy, a constant, prescribed generator inlet water temperature cannot be counted on. Therefore, it is important to know the operating characteristics of air conditioning units under conditions other than those stated by the manufacturer.

The results of tests of various airconditioning units under variable generator inlet temperatures (GIT) are often presented as graphs of the unit's capacity and COP as a function of the GIT, with either the condenser inlet temperature or the chilled water outlet temperature as a parameter. Examples of these graphs are attached (Figures 9-2 and 9-3 [8]). These are steady-state tests; the units are operated with a constant GIT and condenser temperature, and the resulting steady-state chilled water temperature is determined. In practice, the chiller is not turned on until the solarsupplied GIT reaches some minimum temperature (say $160^{\circ} \mathrm{F}$ ) and is allowed to operate with a GIT anywhere within some specified range (say up to $200^{\circ} \mathrm{F}$ ). For this reason transient tests may also be of interest, in which the generator inlet temperature is allowed to rise at a certain rate (simulating startup) or decline (simulating afternoon shutdown). Two modes of operation are possible for such transient tests:

- chilled water flow rate is constant, outlet temperature is allowed to vary; 
Hot Water Manifold

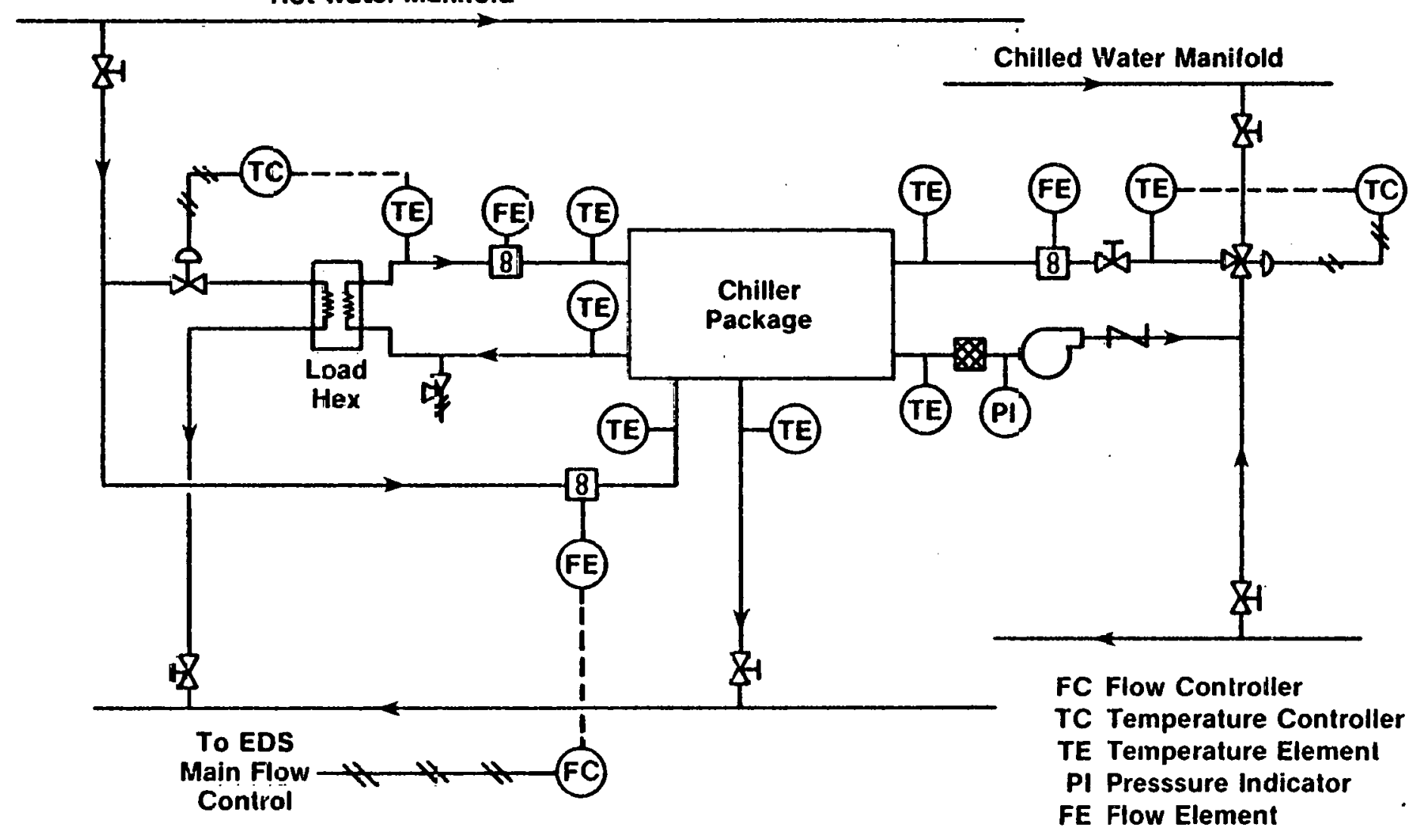

Figure 9-1. EHILLER TEST INSTALLATION AT SERAPH 


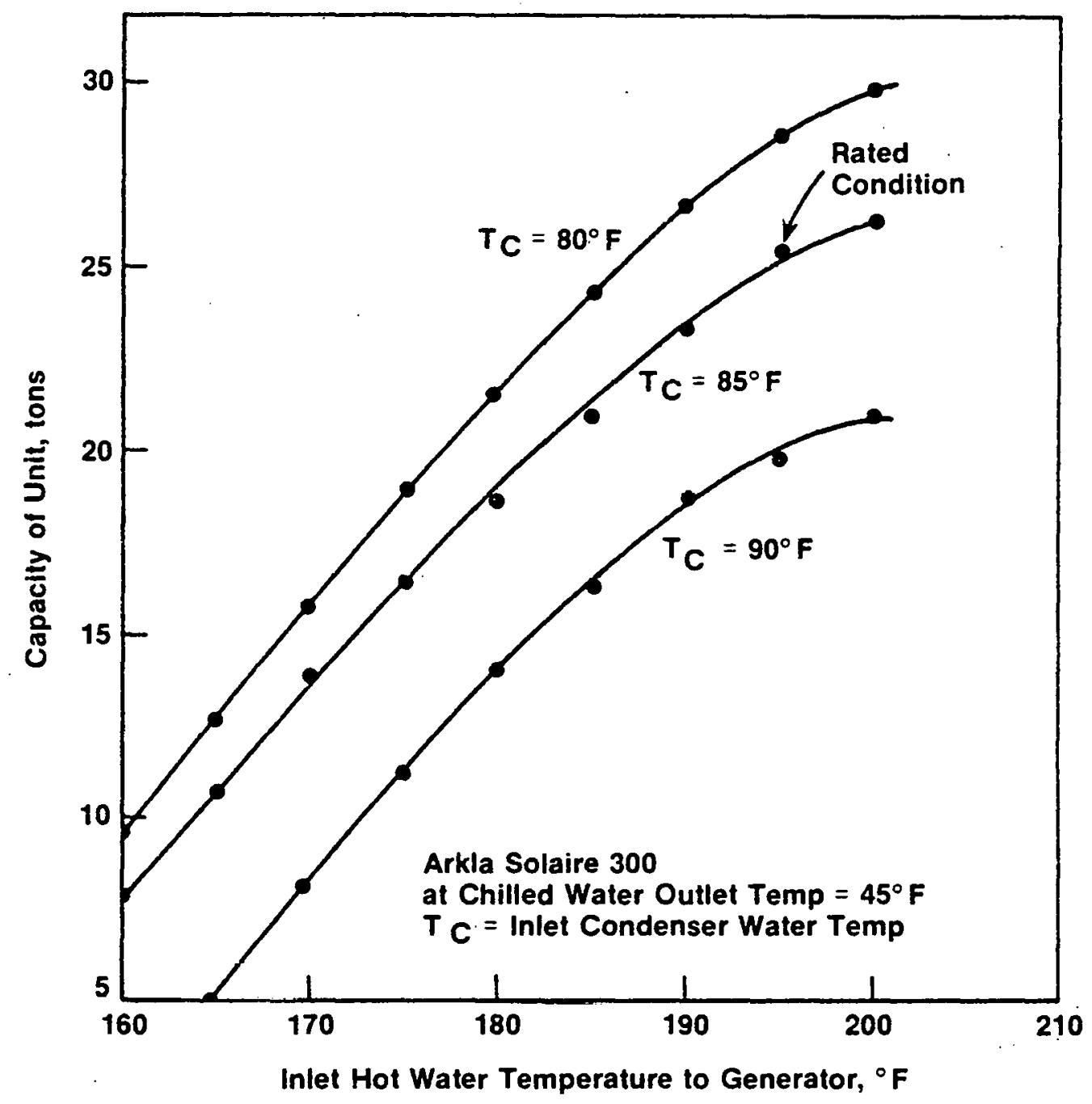

Figure 9-2. CAPACITY OF ARKLA SOLAIRE 300 


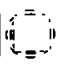

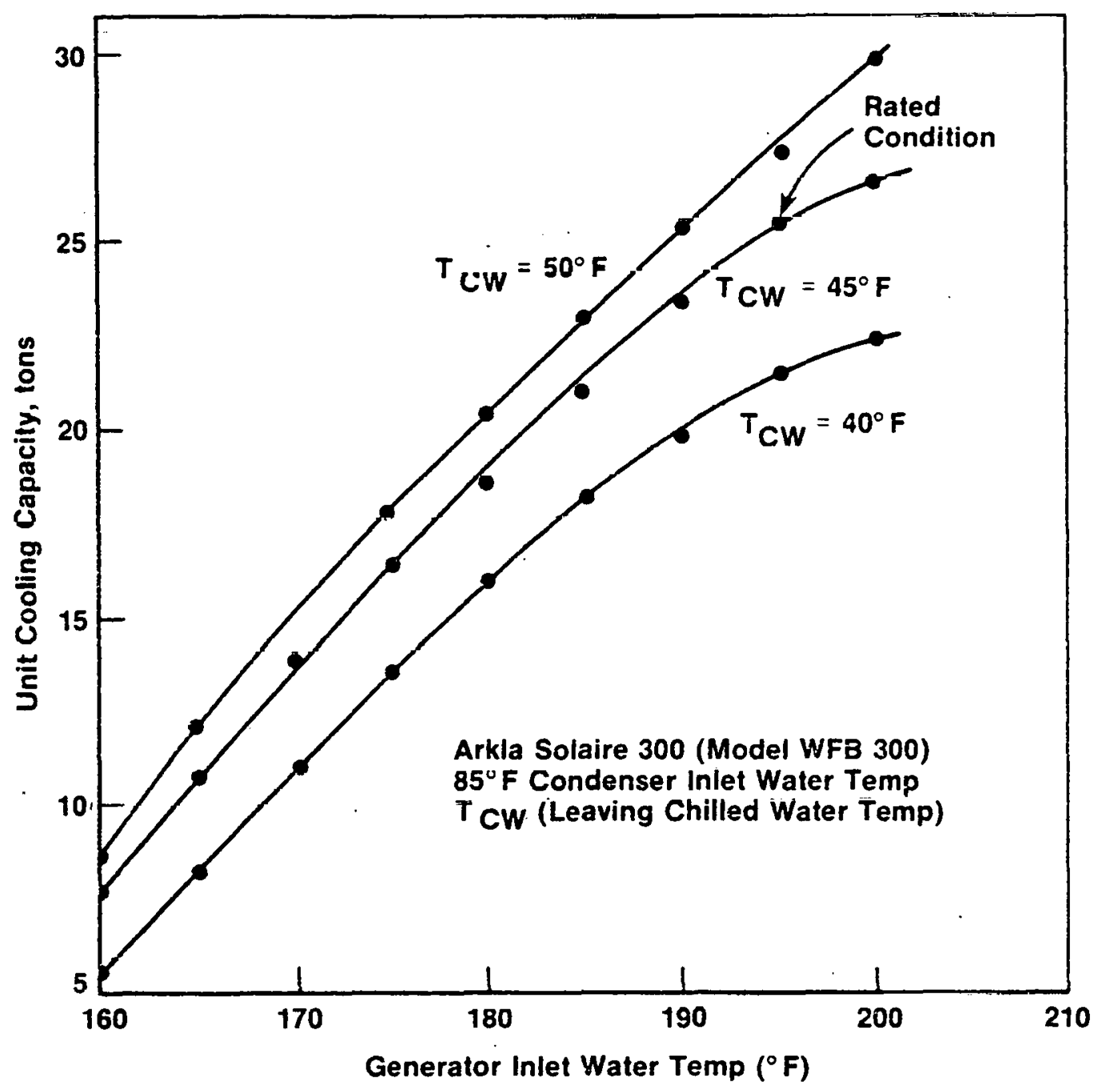

Figure 9-3. UNIT COOLING CAPACITY OF ARKLA SOLAIRE 300 
- chilled water outlet temperature is held constant, either by decreasing the flow rate or recirculating the same water until its temperature is at the desired value.

The second mode seems best since chilled water at too high a temperature will not be useful unless it serves to decrease the average chilled water storage temperature.

Transient tests could also consist of step-changes in the GIT (or condenser temperature) and monitoring the resultant cooling behavior. In either type of transient test the time constant for the unit could be determined.
A third kind of transient test has to do with on/off cycling. Such cycling is typical of systems having less than design loads. Long cycle times lead to losses in capacity since the unit has time to cool down when off, and in each restart the unit must be warmed to its design condition. An example of the amount of zapacity lost is shown in Figure 9-4 [9].

Safety testing is also of interest. For example, what does the unit do if the coolant pump fails? It is important that the unit shut down properly and that no damage is sustained. 


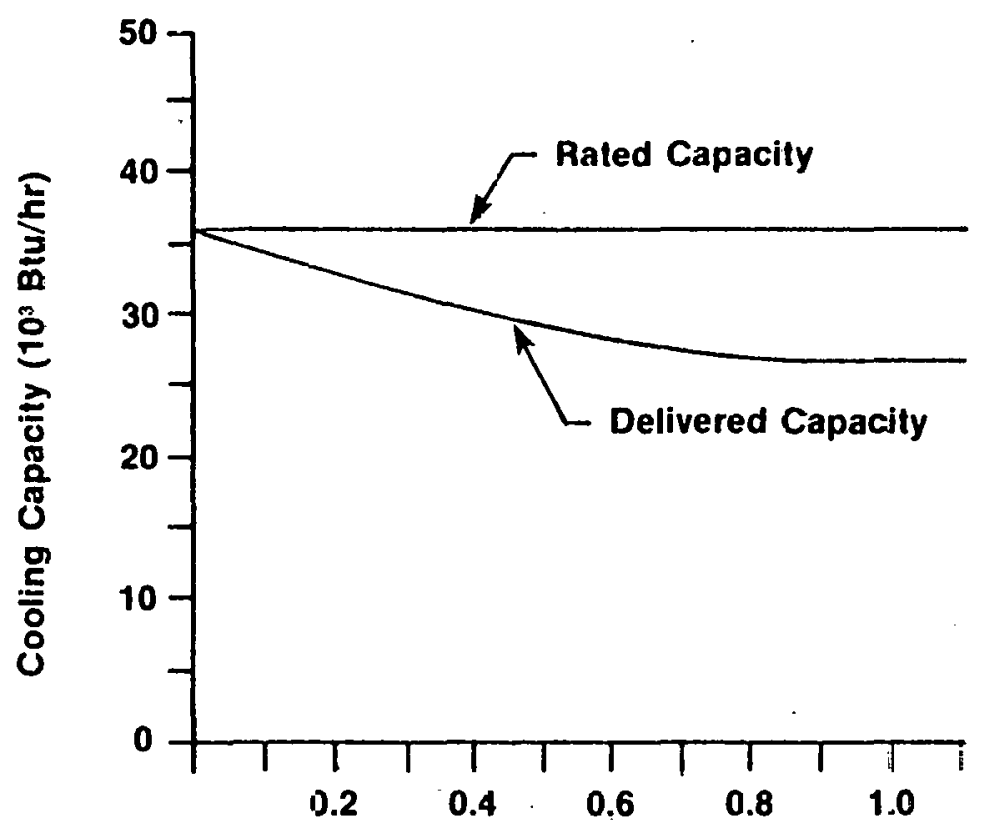

Chiller Operalion Cycle Period (hours)

Figure 9-4. LDSS IN CAPACITY DUE TC ON/CFF CYCLING 


\section{SECTION 10.0}

\section{SAFETY}

Operation of the SERAPH facility introduces conventional industrial safety considerations as well as aspects unique to the collector field. It is important that safety be addressed in a manner which ensures potential industrial solar users that no additional liability is created. SERI should be responsible for identifying issues, selecting conventional approaches for alleviating risk, and recommending new approaches to unique hazards. These actions must be tempered by the fact that a portion of SERAPH will be strictly experimental and that a. large number of visitors may be touring the installation.

Familiar industrial hazards present in SERAPH include:

- corrosive/toxic fluids (storage candidate materials, battery fluid),

- flammable fluids (heat transfer oil),

- pressure vessels and piping,

- oil/gas fired heaters,

- explosive vapors,

- high voltage wiring,

- fuel storage (oil),

- hot valves and components,

- rotating machinery,

- high pressure gas supplies (inert gases), and

- hot fluids.
Safety considerations unique to the collector field result from the concentrated solar flux created by the collector when it is in focus as well as out-of-focus. This flux is a potential fire danger if combustible materials are nearby and is a danger to personnel in terms of eye damage and intense sunburn. Dry vegetation may be ignited by flux concentrations as low as twenty [9]. Figure 10-1 indicates the variable time scale over which sunburns develop as a function of flux intensity [10].

It is expected that the conventional industrial hazards will be addressed by good engineering design and operating procedures which mitigate or preclude potential hazards. Equipment designs will be developed in conformance with existing codes, standards, and recommended practices as set forth by the following groups:

- ASME - pressure vessels and piping, relief valves;

- American Petroleum Institute pumps;

- Uniform Building Code - structures;

- American Welding Institute - weld quality;

- American Institute of Steel Construction - structural steel;

- National Electrical Code - wiring, grounding;

- IEEE - wiring; 


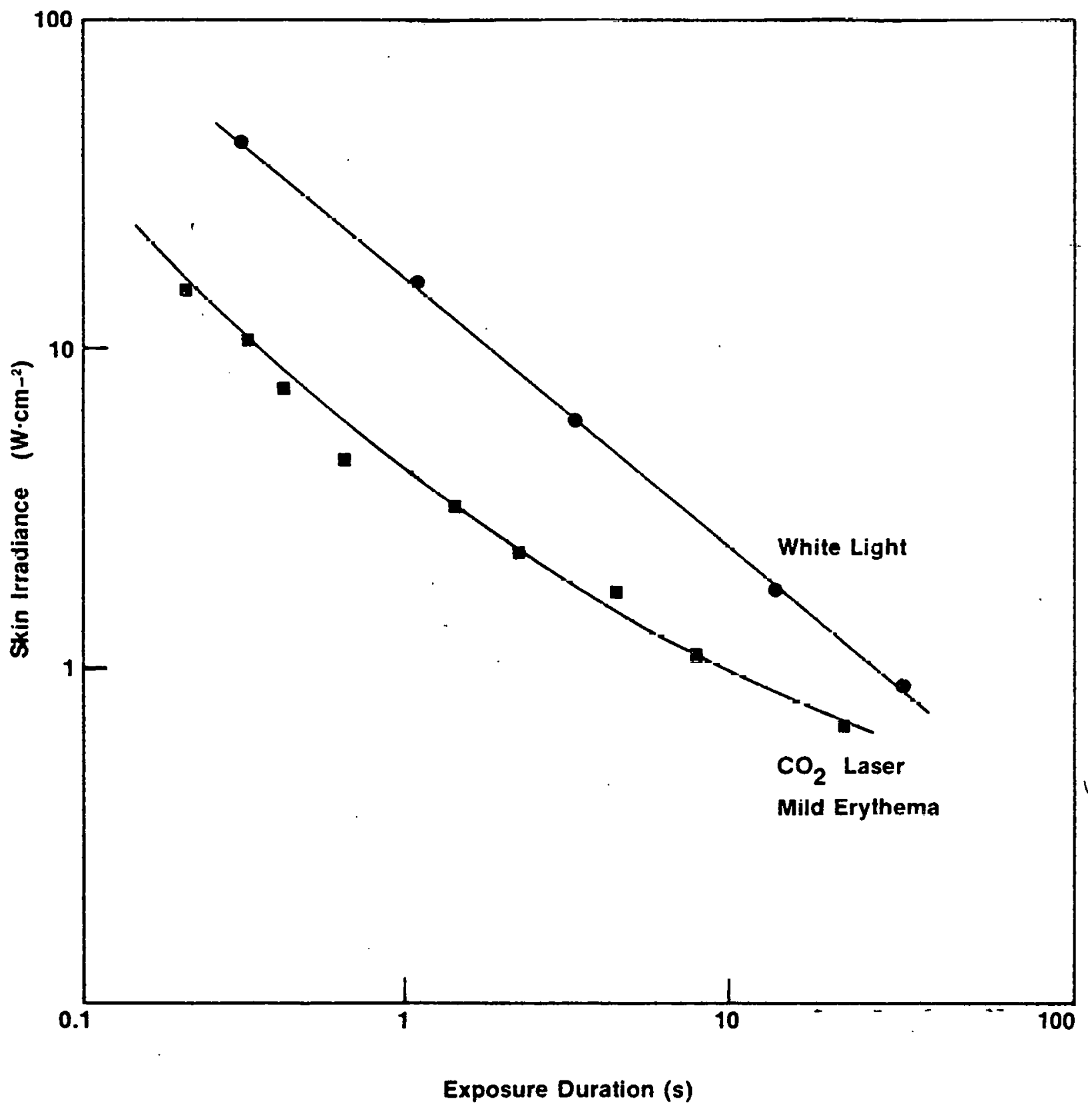

Figure 10-1. TYPICAL LIGHT SOURCES AND EYE DAMAGE THRESHOLDS 
- American National Standards Institute - valves, piping; and

- OSHA - general.

When possible, off-the-shelf equipment approved by organizations such as Underwriters Laboratory or Factory Mutual will be selected. Subsystem operation should follow a printed stepby-step procedure that includes a list of actions to be taken whenever anomalous conditions are detected.

The SERAPH control subsystem will include interlock provisions which prevent certain hazardous actions. An annunciator panel will alert operators to such conditions as excessive temperature, flow interruption, loss of fluid, loss of pressure, high winds, and power failure. A 24 VDC battery backup subsystem will accomplish a limited number of shutdown functions, such as collector storage, in the event of utility power interruption.
An equipment building fire protection system will be compatible with potential fires in the control room, test bay, and heater room.

Personnel protection in the collector field area will be accomplished by physical barriers, warning signs, and the requirement that eye protection be worn inside the barriers. Sandia Laboratories has recommended that eye protection have an optical density of three. Vegetation will be controlled by herbicides or a light, sprayed asphalt coating beneath the collectors. Optical ray-trace calculations will be made to determine the positioning of personnel barriers.

The groups to be protected include the general public, SERAPH visitors, general SERI personnel, and SERAPH personnel. Appropriate personnel will be instructed as to the hazards present, and plans will be developed for actions to be followed in the event of system failures. 
THIS PAGE INTENTIONALLY LEFT BLANK 


\section{SECTION 11.0}

\section{SCHEDULE}

Installation of the basic portions of the SERAPH facility is to take place at the SERI Permanent Field Site in Golden, Colo., during FY79 and FY80. Figure 11-1 indicates the sequence in which individual actions will be taken. The schedule is ambitious in that at the start of FY79 no improvements whatever existed at the SERAPH site. Consequently, a first step will be to erect the SERAPH equipment building as a base from which other activities can grow. The first facility use may be the evaluation of a 25-ton Rankine powered chiller under development in a DOE cooling program. This test may be accomplished by use of the Energy Distribution Subsystem alone, which would allow additional time for installation of the collector field.

The development of SERAPH modeling is not restricted by the equipment schedule and precedes installation of equipment. Computer code development (development of a control strategy) likewise will be conducted while subcontractors are fabricating equipment. 


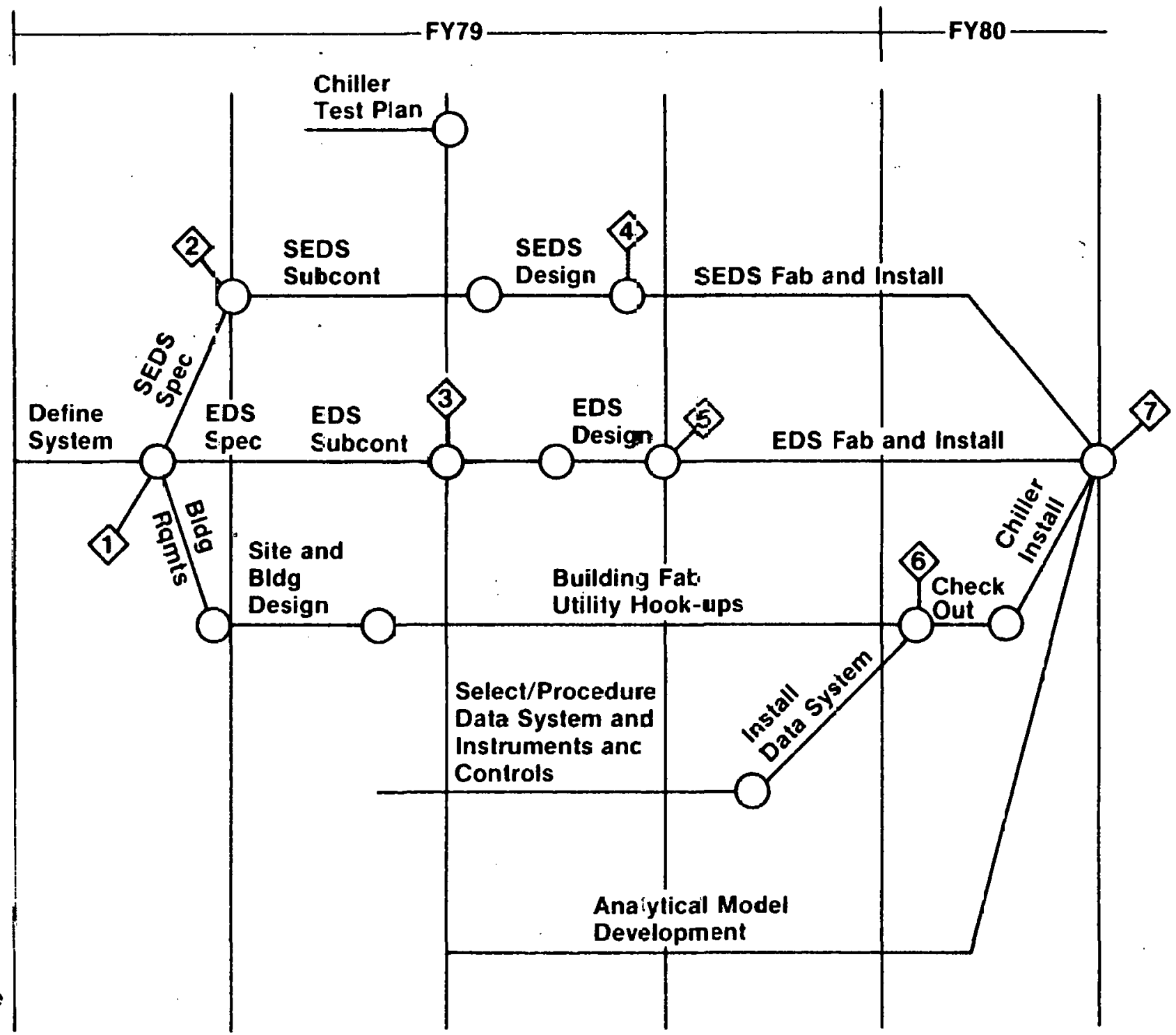

Figure 11-1. FY?9 AND FY80 SERAPH IMPL EMENTATION PLANS 


\section{SECTION 12.0}

\section{DISCUSSION}

The foregoing discussion has provided a description of the planning task carried out at the Solar Energy Research Institute with respect to its SERAPH facility. As emphasized in this discussion, the guiding philosophy has been that the facility shall provide a flexible tool with which a series of engineering and research activities can be conducted.

The ultimate objective is the near-term implem entation of solar thermal technology to meet the vast process heat requirements of U.S. industry. SERAPH will provide a vehicle capable of multiple energy distribution paths between collector field, storage load (either real or simulated load). No fixed energy demands, such as building heating, have been placed on the facility so that no encumbrances are present when new and attractive techniques are suggested for energy manipulation and monitoring within SERAPH.

Design practices will follow current industrial norms to the greatest extent possible, ennsistent with the fact that roeøarch efforts will reruire more sophisticated instrumentation and adaptable control systems. The scale of SERAPH, while small with respect to many potential industrial systems, is sufficiently large that complete system issues can be addressed. Equipment layout is to be such that visitors from industry can readily grasp the role played by each package of equipment.

The Midtemperature Solar System Test Facility (MSSTF) at Sandia Laboratories in Albuquerque, N. Mex., has been a valuable source of operating and design experience influencing the SERAPH facility details. This system, although initially designed to operate as a total energy system (electric power generation, building heat and cooling, as well as hot water generation), provides an experience base on which the SERAPH collector field and the control and data subsystem can build.

Sandia personnel have been cooperative in describing the state of the art in solar systems established at their laboratory. Specific issues and recommendations include:

- Collector field contractors must remain with their system until all operational features are fully debugged.

- Close attention should be given to minimizing parasitic losses occurring at pipe supports, pump cooling jackets, and in daily heatup of components.

- During startup and changes in operating modes a segment of cold fluid may be delivered from a cold pipe with a resultant loss of delivered fluid temperature control.

- Open loop collector position control based upon an ephemeris calculation is superior to closed loop sun-tracker control and two speed tracking is desirable.

- Multitank thermal storage (physical separation of hot and cold fluids) pruvides added system opcrational flexibility. 
- Feedback control loops for maintaining a collector field output temperature set point may perform best if fluid temperature for feedback is monitored within the field rather than at the outlet.

- Large expenditures for leveling collector rows are unwarranted.

- Physical protection is required to prevent insulation damage during hailstorms.

- Próvisions for catching spills of heat transfer oils should be provided.

- Standard power plant practice, such as in the selection of equipment and materials, the definition of hazards, etc., is of ten inadequate or not applicable to solar power systems because of the transient energy input.

- Control valve sizing, selection of packing material, and control valve performance are critical considerations in the control of solar systems.

- Flowmeter installations require adequate upstream and downstream straight runs to minimize noise in the measurement.

- Direct digital control, while not implemented at Sandia, may be beneficial in solar applications.

Sandia personnel also have volunteered to make their solar experience available to SERI during the review of contractor proposals for fabrication of SERAPH subsysteme euch as SEDE and EDE. This cooperation will ensure that SERAPH is built on existing but up-to-date solar technology and does not devote capital expenditures to equipment whose performance has already been shown to be deficient in some respect. Future coordination of research activities will accelerate the rate of accumulation of knowledge specifically applicable to industrial solar systems. 


\section{SECTION 13.0}

\section{REFERENCES}

1. National Program Plan for Research and Development in Solar Heating and Cooling, U.S. Department of Energy, Washington, D.C. (1978).

2. Benham, C. B. and Gupta, B. P. An Experimental System for Solar Energy Research and Applications in Process Heat. Solar Energy Research Institute, SERI-37 (June 1978).

3. Fraser, M. D. Analysis of the Economic Potential of Solar Thermal Energy to Provide Industrial Process Heat. Intertechnology Corporation Report 00028-1 (1977).

4. Klein, S. A. et al. TRNSYS, A Transient Simulation Program. University of Wisconsin, Engineering Experiment Station Report No. 38 (1974).

5. Fewell, M. E. et al. User's Manual for Computer Code SOLTES-1. Sandia Laboratories Report SAND781649 (1978).
6. Brown, K. C. et al. End-Use Matching for Solar Industrial Process Heat. Solar Energy Research Institute SERI/TR-34-091 (to be published 1979).

7. Auh, P. C. A Survey of Absorption Cooling Technology. Brookhaven National Laboratory Report BNL 50704 (July 1977).

8. Hoover, E. L.; Ochs, T.; and Bradley, J. D. A Dynamic Simulation Model of $\mathrm{LiBr}-\mathrm{H}_{2} \mathrm{O}$ Absorption Cooling Devices. Proc. of the Conference on Systems Simulation and Economic Analysis for Solar Heating and Cooling, San Diego, CA (June 1978).

9. Simms, D. L. "Ignition of Cellulosic Materials by Radiation," Combustion and Flame, V.4, 294-320; 1960.

10. Young, L. L. Solar Energy Research at Sandia Laboratories and its Effects on Health and Safety. Sandia Laboratories Report SAND77-1412 (1977). 